RAFAEL AUGUSTO MORENO GONÇALVES

UM MODELO MATEMÁTICO PARA INFERÊNCIA COMPUTACIONAL DE ESTADO EMOCIONAL A PARTIR DE DETECTORES DE EXPRESSÕES FACIAIS 
RAFAEL AUGUSTO MORENO GONÇALVES

\title{
UM MODELO MATEMÁTICO PARA INFERÊNCIA COMPUTACIONAL DE ESTADO EMOCIONAL A PARTIR DE DETECTORES DE EXPRESSÕES FACIAIS
}

\author{
Dissertação apresentada à Escola \\ Politécnica da Universidade de São Paulo \\ para obtenção do título de Mestre em \\ Ciências.
}

São Paulo 
RAFAEL AUGUSTO MORENO GONÇALVES

\title{
UM MODELO MATEMÁTICO PARA INFERÊNCIA COMPUTACIONAL DE ESTADO EMOCIONAL A PARTIR DE DETECTORES DE EXPRESSÕES FACIAIS
}

\author{
Dissertação apresentada à Escola \\ Politécnica da Universidade de São Paulo \\ para obtenção do título de Mestre em \\ Ciências.
}

\author{
Área de Concentração: \\ Engenharia Mecânica \\ Orientador: Prof. Dr. Fábio G. Cozman
}

São Paulo 
Este exemplar foi revisado e corrigido em relação à versão original, sob responsabilidade única do autor e com a anuência de seu orientador.

São Paulo, de julho de 2013.

Assinatura do autor

Assinatura do orientador

FICHA CATALOGRÁFICA

Gonçalves, Rafael Augusto Moreno

Um modelo matemático para inferência computacional de estado emocional a partir de detectores de expressões faciais /

R.A.M. Gonçalves. -- versão corr. -- São Paulo, 2013. $88 \mathrm{p}$.

Dissertação (Mestrado) - Escola Politécnica da Universidade de São Paulo. Departamento de Engenharia Mecatrônica e de Sistemas Mecânicos.

1. Filtros de Kalman 2. Tomada de decisão 3. Inferência 4. Emoções 5. Processamento de sinais I. Universidade de São Paulo. Escola Politécnica. Departamento de Engenharia Mecatrônica e de Sistemas Mecânicos II. t. 


\section{AGRADECIMENTOS}

Ao professor Fábio Cozman pela orientação e serenidade durante todo o trabaIho. Aos professores Marcos Barretto e Francisco Nigro, cujos ensinamentos foram além da Engenharia.

Ao grande amigo Diego Cueva, por partilharmos as alegrias e frustrações de nossas empreitadas.

A meus pais e à Silvia, por apoiarem incondicionalmente as decisões que me fazem feliz. 


\section{RESUMO}

Este trabalho apresenta um modelo matemático para a inferência do estado emocional de um usuário ou interlocutor com base em suas expressões faciais. O modelo apresentado consiste em dois estágios básicos, responsáveis pelo tratamento de sinais e sua integração, respectivamente. No primeiro estágio, filtros de Kalman independentes são utilizados para o processamento paralelo dos sinais relativos às expressões faciais emocionais. O estágio de integração, por sua vez, aplica os sinais filtrados a um sistema no qual uma partícula desliza sobre uma superfície a qual representa os estados e transições emocionais. O estado emocional do interlocutor é inferido, quadro a quadro, por meio da inspeção da posição instantânea da partícula. Uma heurística de simulaçãootimização baseada em recozimento simulado (simulated annealing), é introduzida a fim de automatizar o processo de ajuste dos parâmetros do modelo em conformidade com o algoritmo de detecção de expressões faciais escolhido. $O$ modelo proposto foi validado utilizando-se um corpus contendo 51 vídeos. Os resultados são comparados à classificação realizada por um grupo de voluntários, correspondendo a esta em $92 \%$ dos casos. 


\begin{abstract}
This work presents a mathematical model for emotional state inference based solely on facial expressions. The presented model consists of two basic steps, which are responsible for signal processing and its integration, respectively. During the former, independent Kalman filters are employed for parallel processing of emotional facial expression related signals. The later step, integration, applies those filtered signals to a system where a massless particle slides along a surface representing the emotional states of interest and its transitions. The subject's emotional state is inferred from the particle's instantaneous position at each frame. A simulation-optimization heuristic based on simulated annealing is introduced as for fully automatic parameter tuning technique, which allows for easily coupling between the proposed model and different facial expression detection algorithms. The proposed model is validated against 51 multimodal emotional videos. The results are compared to human-based classification and a $92 \%$ agreement rate is observed.
\end{abstract}




\section{LISTA DE FIGURAS}

Figura 1: Categorias de Emoções Propostas por Goleman, [apud MartinezMiranda, 2005]..................................................................... 27

Figura 2: Campo AV extraído de [Feldman, 1993]

Figura 3: Modelo de resposta para "atacar ou fugir". À esquerda a superfície que modela o comportamento para tal situação, à direita as expressões associadas no comportamento de um lobo. Extraído de [Sander et al, 2005]. 28

Figura 4: Cadeia de processamento de dados em sistemas de classificação de expressões faciais, [Fasel et al, 2003]

Figura 5: Classificadores em cascata. Segmentos que não contêm faces são rejeitados no início do processamento, diminuindo o custo computacional, [Viola et al, 2004].

Figura 6: Relação entre índice de detecção e taxa de falsos positivos para um classificador monolítico e um classificador em cascata, [Viola et al, 2004].

Figura 7: Malha de extração de elementos faciais utilizada pelo software eMotion. [REFERENCIA] 38

Figura 8: Extração de deformação por meio de ondaletas de Gabor, [Fasel et al, 2003].

Figura 9: Extração de movimento por meio de técnicas de fluxo ótico, [Fasel et al, 2003]. Destaca-se a assimetria acentuada na movimentação da região inferior da face no segundo caso de análise.

Figura 10: Problema de janelamento na análise de estados emocionais,

[Baltrusaitis, 2011].

Figura 11: Rede Bayesiana utilizada para inferência de estados mentais de alunos durante uma aula, com base em sua linguagem corporal,

[Abbasi et al, 2009]

Figura 12: Transições de estados mentais e observações sensoriais, [Abbasi et al, 2009].

Figura 13: Pipeline de processamento de dados 
Figura 14: Imagens do vídeo ilustrativo. As imagens, da esquerda para a direita, foram classificadas pelo eMotion como felicidade (100\% de certeza, aos $2,36 \mathrm{~s})$, tristeza $(70,6 \%, 0,76 \mathrm{~s})$, medo $(83,1 \%, 3,92 \mathrm{~s}) \mathrm{e}$

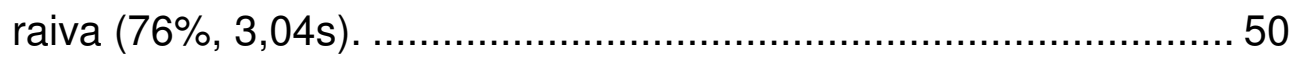

Figura 15: Saídas do eMotion para o vídeo ilustrativo. ................................... 50

Figura 16: Exemplo de curva de dinâmica emocional ......................................5 55

Figura 17: Concordância na Classificação Humana de Amostras de Vídeo

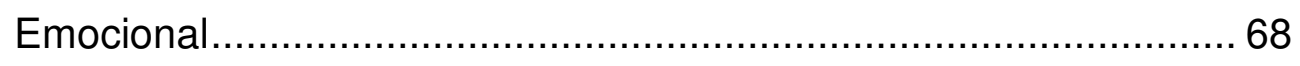

Figura 18: Interface do aplicativo eMotion durante a análise de um vídeo....... 70

Figura 19: Convergência para a melhor solução obtida utilizando a heurística de simulação-otimização proposta.

Figura 20: Dados do filtro ilustrativo após filtragem. A linha contínua representa o filtro de Kalman e a linha tracejada o filtro de média móvel. ........ 74

Figura 21: Descrição do Estado Emocional com Base em Quadrantes ........... 76

Figura 22: Trajetórias emocionais para os casos 1 (esquerda) e 5 (direita).... 78

Figura 23: Trajetórias emocionais para os casos 7 (esquerda) e 10 (direita)... 78

Figura 24: Trajetória emocional para o caso 14, falha. 79 


\section{LISTA DE TABELAS}

Tabela 1: Classificação Manual no Experimento de Análise Semântica dos Vídeos de Felicidade

Tabela 2: Classificação Manual no Experimento de Análise Semântica dos Vídeos de Tristeza.

Tabela 3: Classificação Manual no Experimento de Análise Semântica dos

Vídeos de Raiva 66

Tabela 4: Classificação Manual no Experimento de Análise Semântica dos Vídeos de Medo

Tabela 5: Matriz de Confusão do Experimento de Classificação Manual.......... 68

Tabela 6: Concordância para Cenários de Classificação Forçada, extraído de [Russel, 1994]

Tabela 7: Resultados da heurística de ajuste dos filtros ................................ 72

Tabela 8: Parâmetros dos Filtros de Kalman para Dados do eMotion .............. 73

Tabela 9: Posicionamento dos Atratores......................................................... 76

Tabela 10: Resultados do Experimento .................................................... 77 


\section{SUMÁRIO}

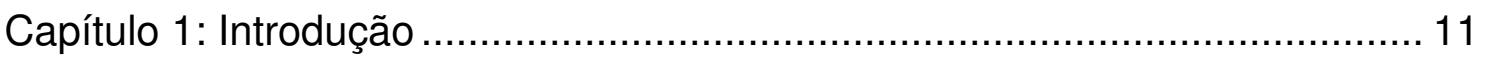

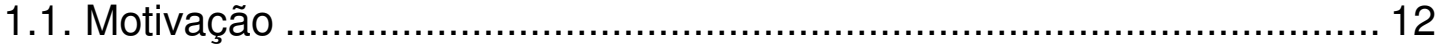

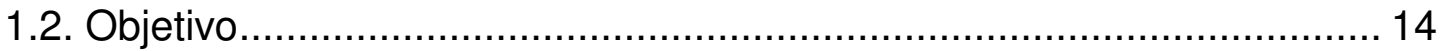

1.3. Contribuição.......................................................................... 14

1.4. Estrutura do Trabalho ................................................................ 15

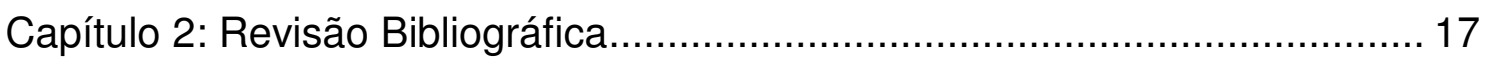

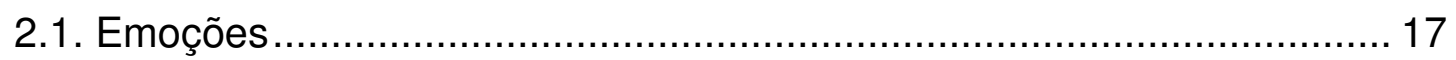

2.1.1. Interpretação Evolucionista .............................................. 19

2.1.2. Teorias Sentimentalistas ............................................... 21

2.1.3. Abordagens Psicológicas ....................................................... 23

2.1.4. Teorias Cognitivas............................................................. 24

2.1.5. Teorias de Percepção ............................................................ 25

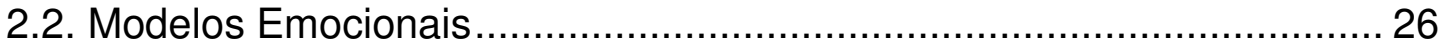

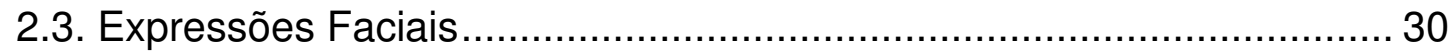

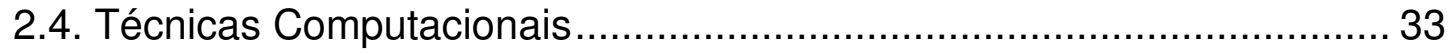

2.4.1. Detecção Facial........................................................... 34

2.4.2. Extração de Elementos Faciais e Classificação de Expressões ..... 37

2.4.3. Inferência de Estados Emocionais ...................................... 41

Capítulo 3: Modelo Proposto ......................................................... 48

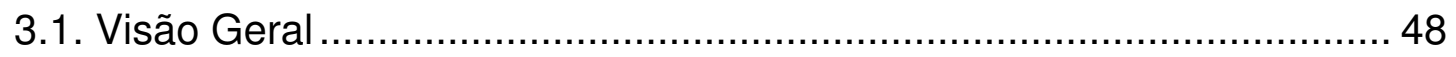

3.2. Captura de Vídeo e Detecção de Expressões Faciais........................... 49

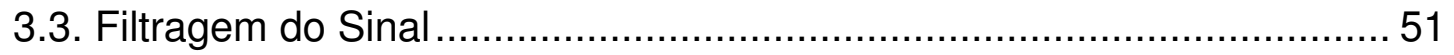

3.4. Estimação do Estado Emocional ................................................... 54

3.5. Ajuste Automático dos Filtros .................................................. 57 


\section{Capítulo 1: Introdução}

Máquinas inteligentes, robôs presentes no cotidiano de famílias de classe média, carros voadores, sistemas de representação de conhecimento, reconhecimento robusto de voz, entre outros, são parte das promessas tecnológicas não entregues feitas aos nascidos nas décadas de setenta e oitenta. $\mathrm{Na}$ verdade, basta assistir aos programas infantis de hoje em dia para ver que tais promessas continuam em voga e replicam-se nas mentes da geração atual.

A despeito de todo esse trabalho da mídia, da existência destes seres tecnológicos na imaginação de grande parte da população mundial e do desejo manifesto por várias destas aplicações, sua concretização acena muito distante. Por hora, cabe à humanidade satisfazer-se com dispositivos que exibem subconjuntos de tais funcionalidades e possuem desempenho muito inferior ao ideal.

Os desafios no escopo da inteligência artificial são muito mais complexos que o estimado em um primeiro momento. Embora o número de pesquisadores, publicações e grupos dedicados à área seja vasto, tanto na academia quanto comercialmente, as pesquisas têm, consistentemente, levado a novas questões ao invés de soluções simples para problemas como reconhecimento de padrões, memória, aprendizado, consciência, entre outros.

Progressos existem: hoje são comuns carros e telefones celulares que aceitam comandos de voz, os frutos das pesquisas em reconhecimento de padrões e representação do conhecimento são colhidos todos os dias na área de mineração de dados (data mining), os avanços em visão computacional beneficiam desde processos industriais e hospitalares até consoles de jogos (video games). Diversos outros exemplos podem ser mencionados e todas estas inovações são fruto da persistência na pesquisa e também da tática "dividir para conquistar".

Assim sendo, cabe ao pesquisador nas áreas de inteligência artificial, robótica sociável ou computação afetiva aplicar-se ao desenvolvimento incremental de seus campos de interesse, na esperança de colaborar à concretização do futuro que the foi prometido.

Ao longo deste trabalho, o problema de inferência do estado emocional dos interlocutores será observado e analisado à luz da correlação entre este e 
as expressões faciais cotidianas. Utilizando tais expressões como pistas, propõe-se uma arquitetura e algoritmos para uma implementação computacional que sirva aos propósitos da computação afetiva e da robótica sociável.

\subsection{Motivação}

Emoções estão presentes no cotidiano dos seres humanos. Sejam elas resultantes da iteração com o mundo, do choque entre expectativas e realidades, da antecipação de ações e comportamentos, de mecanismos de autopreservação ou da presença de consciência, as emoções apresentam-se como característica da espécie. Ainda assim, emoções são tratadas com certo estigma pela ciência, cujo método remete ao pensamento racional [Picard, 1995].

Naturalmente, tópicos como a origem, o significado, os mecanismos neurológicos e os distúrbios relacionados às emoções são, em si, objetos de pesquisa há séculos. De fato, emoções foram tema de estudo de alguns dos mais famosos filósofos da história, como Aristóteles, Descartes e Spinoza. De acordo com a tradição de pensamento funcionalista aristotélica, na qual estas são avaliações cognitivas de eventos, a maior parte dos trabalhos filosóficos desde então se concentra nos aspectos cognitivos das emoções [Oatley, 1999].

Charles Darwin [Darwin, 1872] defende a presença de emoções no cérebro animal utilizando a teoria evolucionista: emoções se estabeleceram por propiciar melhores chances de sobrevivência e reprodução àqueles que reagiam a eventos e mudanças no ambiente. Darwin, porém, conclui que, em seres humanos, emoções e sua expressão são comportamentos equivalentes a órgãos vestigiais, decorrentes do desenvolvimento individual, e que estão presentes na vida adulta, sejam úteis ou não. O estigma sobre as emoções intensificou-se com o surgimento da psicanálise, quando trabalhos de Freud muitas vezes abordavam desordens emocionais. Credita-se à psicanálise o reconhecimento do poder das emoções no ser humano, estudando tais distúrbios e desordens de forma científica.

Mais recentemente, abordagens cognitivas demonstraram que as emoções desempenham papel ativo nos processos cognitivos e sociais, tipica- 
mente colaborando com processos racionais, ao invés de demostrarem-se tipicamente irracionais e disfuncionais [Oatley, 1999].

Ainda assim, embora Aristóteles, Le Brun, Duchenne e outros [apud Russell, 1994] tenham admitido a hipótese de universalidade das expressões faciais relacionadas a emoções, a obra "Expression of Emotion in Man and Animals" [Darwin, 1872], é o trabalho fundamental sobre o tema. Diversos contra-argumentos, baseados ou não em observações experimentais, foram propostos no longo debate quanto à universalidade, mas, por fim, a tese foi aceita na psicologia moderna e o tópico já não é mais discutido [Matsumoto, 1990].

Em realidade, o debate foi resolvido em grande parte graças aos experimentos como os realizados por Ekman, demonstrando que diversas culturas são capazes de reconhecer expressões fundamentais de felicidade, tristeza, nojo, raiva, medo e surpresa com chances bastante superiores a uma distribuição aleatória [Ekman et al, 1972]. De fato, tais estudos, em paralelo com a elaboração de um atlas facial e uma linguagem de descrição da atuação facial, sob o nome de FACS: Facial Action Coding System, [Ekman et al, 1978], possibilitaram o desenvolvimento de técnicas forenses de análise. Finalmente, a identificação de emoções a partir de expressões faciais chegou ao grande público em 2009, com a estreia do seriado Lie to Me, da FOX, sobre um grupo de consultores especializados em identificação de fraudes por meio das técnicas desenvolvidas por Ekman.

Embora identificar fraudes, mentiras e criminosos tenha seu apelo dramático, as implicações da relação entre emoções e expressões faciais, bem como de sua universalidade, apresentam diversas outras possibilidades. Treinamento de atores, detecção de possíveis focos de confusão em estádios, diagnóstico de desordens neurológicas, refinamento de animações em realidade virtual, entre outros. Estas e outras aplicações motivaram, ao longo das últimas décadas, diversas tentativas de identificação de expressões faciais por meio de técnicas computacionais, utilizando imagens estáticas ou sequencias de vídeo. Boas compilações de métodos e resultados podem ser obtidas em [Pantic et al, 2000] e [Fasel et al, 2003].

Mais recentemente, tanto a Computação Afetiva (Affective Computing) quanto a Robótica Sociável (Sociable Robotics), elegeram a capacidade de 
interpretar sinais emocionais de interlocutores e reagir de acordo com eles em um contexto apropriado como desafios a serem superados nos paradigmas de iteração homem-máquina, [Picard, 2003] e [Breazeal, 2003], respectivamente. É importante ressaltar que ambas referenciam o problema mais complexo de estimação do estado emocional do interlocutor a partir de sinais como, por exemplo, as expressões faciais, tópico ainda emergente quando da redação deste trabalho.

\subsection{Objetivo}

O presente tem por objetivo a inferência do estado emocional de um interlocutor ou usuário, utilizando sensores não intrusivos para o aprimoramento das interfaces homem-máquina.

\subsection{Contribuição}

A contribuição deste trabalho consiste em um algoritmo para inferência de estados emocionais por meio do pós-processamento de expressões faciais. Diferentemente dos trabalhos apresentados no levantamento bibliográfico, em especial na Seção 2.4.3, utiliza-se um modelo contínuo para a representação dos estados do sistema.

O modelo proposto permite o pós-processamento de algoritmos de deteç̧ão de expressões faciais por meio da aplicação de filtros de Kalman independentes a cada uma das emoções analisadas. Após filtrados, os sinais são integrados no tempo por meio de um sistema de primeira ordem representado por uma partícula deslocando-se sobre uma superfície. O estado emocional do interlocutor é inferido continuamente a partir da posição desta partícula em cada instante.

Adicionalmente, uma heurística de simulação-otimização é apresentada para o ajuste automático dos parâmetros de cada um dos filtros utilizados. 


\subsection{Estrutura do Trabalho}

O presente trabalho foi estruturado de forma a apresentar, inicialmente, as contribuições propostas à luz dos resultados contemporâneos nas áreas correlatas, sobretudo a identificação de expressões faciais e inferência emocional, dando ênfase aos avanços e objetivos recentes da robótica sociável e da computação afetiva.

Assim sendo, o Capítulo 2 apresenta uma revisão bibliográfica a fim de estabelecer os conceitos fundamentais sobre emoções e expressões faciais. Segue-se, então, uma discussão a respeito dos métodos computacionais de detecção de expressões faciais e emoções encontrados na literatura, a qual permite ao leitor compreender o modelo proposto para inferência dos estados emocionais.

O Capítulo 3 introduz formalmente o modelo proposto. Inicialmente apresenta-se uma visão geral que permite ao leitor identificar e familiarizar-se com os componentes da arquitetura proposta, seguido de uma discussão aprofundada sobre as escolhas que a fundamentam. Realiza-se então o detalhamento do algoritmo proposto para a inferência do estado emocional do interlocutor por meio de filtragem de sinais e um modelo dinâmico subjacente. O modelo é complementado por uma heurística computacional de simulaçãootimização para ajuste automático dos parâmetros envolvidos, processo este que pode ser interpretado como uma etapa de aprendizado e treinamento.

A validação do modelo é apresentada no Capítulo 4, de forma a demonstrar a aplicação do modelo e analisar os resultados quando do processamento de sequências de vídeo. O estudo de caso se inicia com a seleção de vídeos multimodais representativos, processo no qual um grupo de voluntários assiste um conjunto pré-selecionado de sequências de vídeo e as classifica individualmente quanto ao conteúdo emocional. Os resultados obtidos nesta classificação são comparados àqueles apresentados na literatura a fim de determinar se o videoclipe transmite ou não a emoção adequadamente.

Os vídeos para os quais a classificação humana mostra-se adequada são analisados por meio de um aplicativo comercial de deteç̧ão de expressões faciais. Os resultados são divididos em um conjunto de treinamento e um conjunto de teste. A rotina de ajuste de parâmetros é aplicada utilizando-se o pri- 
meiro conjunto e o modelo proposto é utilizado na classificação dos vídeos restantes. Os resultados são apresentados e discutidos.

Por fim, o Capítulo 5 apresenta comentários finais acerca do trabalho e propõe desenvolvimentos futuros. 


\section{Capítulo 2: Revisão Bibliográfica}

Neste capítulo, os principais conceitos necessários à fundamentação teórica e ao entendimento do modelo proposto são expostos por meio de uma revisão bibliográfica. Assim, o capítulo não aspira a uma revisão extensiva sobre Emoções ou Expressões Faciais, mas oferece informações necessárias ao restante do trabalho e à compreensão dos modelos propostos e adotados.

\subsection{Emoções}

Embora a existência de emoções seja uma característica comum aos mamíferos, presente no Homo Sapiens e seus ancestrais, somente com as escolas filosóficas helênicas a cultura ocidental passa a oferecer explicações formais sobre o papel que as emoções desempenham no cotidiano humano, [Damásio,1994]. Desde então, vêm sendo objeto de estudo de áreas como a filosofia, psicologia, psiquiatria, biologia, neurociências e, a partir da segunda metade do século XX, das ciências cognitivas. É importante ressaltar de que não há uma teoria universalmente aceita, [Picard, 2001], portanto, este capítulo aborda algumas das principais proposições sobre o tema.

Para Aristóteles [apud de Sousa, 2010], as emoções não representam, em si, uma faculdade independente na mente, mas ainda assim são importantes, particularmente por sua participação na moral, definida pelo filósofo como "o resultado de aprender a sentir as emoções corretas diante das circunstâncias". A defesa de emoções como crenças inerentemente irracionais é atribuída aos Estóicos e Epicuristas. Dessa forma, sendo a irracionalidade a fonte de todos os sofrimentos e vícios, ambas as escolas sugerem a incompatibilidade entre uma vida boa e as emoções [de Sousa, 2010].

Diversas teorias filosóficas convivem nas discussões sobre o tema. Kant, [Kant, 1785], propõe que emoções são um dos mecanismos responsáveis por direcionar a vontade humana a agir de acordo com motivações diferentes do dever. Spinoza [apud. Neu, 1977] atribui às emoções o papel de efeitos que agem sobre alma, aumentando ou diminuindo a capacidade de atuação desta, responsáveis por diferenciar o melhor e o pior da vida. Outras teorias 
relegam as emoções a uma categoria específica de crença, ou a um sentido vago de desejo ou vontade.

De toda maneira, Spinoza aponta prontamente que o espectro de variações emocionais em dimensões como transparência, intensidade, expressão comportamental, direcionamento e susceptibilidade a análise racional leva a dúvidas quanto à hipótese de teoria unificada de emoções.

Outra discussão em aberto diz respeito à relação entre razão e emoção e ao direcionamento das emoções a objetos focais ou de forma. Determinados cenários apresentam dificuldades substanciais às teorias atuais, como, por exemplo, emoções sujeitas a racionalizações e justificativas ou ainda o caso em que alguém demonstra raiva diante da interpretação subjetiva da opinião de um terceiro [de Sousa, 2010]. Segundo o autor, a maneira correta de lidar com tais complexidades é abraçando-as ${ }^{1}$. O autor defende a necessidade de uma taxonomia para o que ele define como objetos emocionais, a fim de distinguir diferentes tipos de emoção não somente com base em questões qualitativas, mas também na estrutura semântica inferida da relação entre tais objetos. Assim, por exemplo, enquanto certas emoções como "amor" e "afeto" implicam na existência de um objeto focal, ao qual são direcionadas, outras, como "tristeza" ou "felicidade", não. Em realidade, o autor, sustenta que estas últimas podem ou não se referir a um objeto proposicional, enquanto ao "arrependimento" tal objeto é indispensável.

Finalmente, enquanto os objetos acima podem ou não estar presentes para uma dada emoção, toda emoção possui um objeto de forma ${ }^{2}$, definido como uma propriedade implicada pela emoção a seu alvo, foco ou objeto proposicional, em virtude da qual ela possa ser entendida. Assim o medo que é sentido em razão de um cão latindo, salivando e eriçando os pelos é explicado pela percepção do animal como ameaçador. Desta forma, a tautologia é inserida como aspecto fundamental da definição de objetos formais - eu sinto nojo de algo, porque algo é nojento, ou, eu sinto medo de algo, porque algo é amedrontador -, mas, ainda mais importante, insere-se o conceito de emoções

\footnotetext{
${ }^{1}$ No original: "The right way to deal with these complexities is to embrace them.".

${ }^{2}$ Nesse contexto, mesmo que o termo "formal" se apresente como sinônimo válido, ele será preterido a fim de evitar compreensões erradas advindas de seu contraponto a "informal" e "casual".
} 
apropriadas. Se no exemplo acima tratássemos de um filhote brincalhão, o "medo" não estaria correspondendo a seu objeto formal; em outras palavras 0 sujeito estaria sentindo medo de algo que não é tido como amedrontador e, logo, tal emoção não seria apropriada à situação. $O$ autor aponta ainda que 0 fato de determinada emoção ser apropriada reside nos valores do sujeito que a sente e não na moral. Assim, o nojo advindo do racismo é inapropriado do ponto de vista moral, ainda que se trate de uma emoção apropriada. Tal consideração coloca a conclusão em contraponto ao argumento oferecido pela escola aristotélica.

Em sua análise extensiva sobre o tema, [de Sousa, 2010] classifica as teorias emocionais em cinco grupos distintos, os quais serão expostos a seguir nos próximos itens.

\subsubsection{Interpretação Evolucionista}

O próprio Charles Darwin utilizou-se da teoria evolucionista para explicar a presença de emoções no cérebro animal, mas concluiu que, nos seres humanos adultos, elas assemelham-se a órgãos vestigiais, remanescentes de comportamentos cuja função não exibe necessariamente utilidade em termos evolutivos, [Darwin, 1872]. Darwin concentrou-se, porém, em discutir não a origem ou o papel das emoções nos seres humanos, mas o porquê de sua expressão da forma que se conhece.

Assim, Darwin defende que as expressões fisiológicas das emoções foram selecionadas segundo a teoria da evolução de forma que o cerrar dos dentes e aumento dos batimentos cardíacos na expressão de raiva preparam o animal para a ação que pode vir a tomar. Além disso, ao comunicar as intenções do animal, as expressões faciais constituiriam, portanto, em um meio de comunicação.

Em um nível funcional, a questão primordial refere-se à utilidade das emoções. É geralmente aceito que o papel das emoções básicas, conforme identificado por [Ekman, 1992], [Ekman et al, 1972] e [Ekman et al, 1986], é relacionado às necessidades biológicas básicas tais como evitar predadores, acasalar, defender-se e integrar-se socialmente. Darwin, [Darwin, 1872], ressal- 
ta que os mamíferos de modo geral apresentam processos emocionais estereotipados para lidar com tais situações.

É defendido em [Ekman et al, 1972] que estes processos emocionais, ou, segundo a nomenclatura de [de Sousa, 2010], "programas de efeito" ${ }^{3}$, sejam de fato a própria definição de emoção. Novamente, tal visão encontra-se fortemente embasada na interpretação evolucionista e está sujeita aos mesmos criticismos, em especial sua inadequação para explicar o que [Griffiths, 1997] identificou como "emoções penetráveis à cognição" 4 .

Cada um destes programas de efeito compreende, segundo [de Sousa, 2010], respostas coordenadas em níveis fisiológicos, hormonais, neurológicos, musculares e expressivos.

Do ponto de vista das neurociências, por sua vez, a aceitação das emoções como uma entidade neurobiológica acontece em grande parte graças aos trabalhos de MacLean, que apresenta argumentos a favor da existência de um sistema cerebral especializado para emoções [MacLean, 1952]. Tal sistema seria composto basicamente de estruturas cerebrais mais antigas, em termos evolucionários, presentes em regiões do córtex medial e regiões subcorticais interconectadas, como o hipotálamo. MacLean o batizou de "cérebro visceral" [apud Brothers, 2012]. Posteriormente, tais estruturas foram denominadas sistema límbico.

Embora nos anos seguintes diversos estudos tenham abordado quais estruturas e regiões do cérebro fariam ou não parte do sistema límbico, o consenso atual é de que não é possível definir um critério anatômico, funcional ou comportamental capaz de agrupar única e exclusivamente as regiões cerebrais envolvidas no processamento emocional. Este fato, conforme argumentado por LeDoux, [apud. Brothers, 1999] coloca em dúvida se a hipótese de existência de um sistema límbico como proposto ainda é válida nos dias de hoje.

A interpretação em [James, 1884], de que não existiria uma estrutura cerebral especial para as experiências emocionais, mas que as mudanças corporais em razão de estímulos internos ou externos ao serem percebidas pelo

\footnotetext{
${ }^{3}$ NT: Em [de Sousa, 2010] é utilizada a expressão "affect programs", todavia sua definição reside no efeito percebido, logo a tradução utilizada, "programas de efeito", apresenta-se mais adequada ao entendimento.

${ }^{4}$ No original: "cognitively penetrable emotions".
} 
córtex sensorial são a origem e a definição das experiências emocionais, recebe apoio parcial, como em [Hess et al, 1992], [Kurth et al, 2010]. Ambos aceitam a ideia de que o corpo desempenha um papel, mas também acreditam que existem estruturas particulares no cérebro, especializadas em experiências e comportamentos emocionais.

A percepção, interpretação e expressão de emoções, assim como o próprio comportamento emocional em si, também são áreas de estudo das neurociências. Hoje é consenso que o hemisfério direito parece predominar tanto no que diz respeito à produção quanto à percepção das emoções, tanto por meios de expressão vocais quanto faciais. Na realidade, cogita-se que o córtex temporal direito possa ter uma região especializada à interpretação de expressões faciais associadas às emoções [Brothers, 1999].

\subsubsection{Teorias Sentimentalistas}

O senso comum a respeito de emoções é representado pela família de teorias sentimentalistas, para as quais as emoções consistem em uma categoria especial de sentimentos e sua diferenciação dá-se através das sensações e das propriocepções qualitativas experimentadas.

Uma variante particular das teorias sentimentalistas é apresentada por William James [James, 1884]. James postula que as emoções são sentimentos advindos de mudanças fisiológicas, em especial àquelas relacionadas aos sistemas autonômicos (controle da respiração, batimentos do coração, entre outros) e ao sistema motor. Assim, ao percebermo-nos em uma situação de perigo, uma série de processos é desencadeada no corpo e nossa percepção da ocorrência desses processos é denominada medo. A implicação da teoria de James é, segundo o próprio autor: "nós nos sentimos culpados porque choramos, nervosos porque atacamos, amedrontados porque trememos e não choramos, atacamos ou trememos por estarmos nos sentindo culpados, nervosos ou com medo, como pode parecer"

\footnotetext{
${ }^{5}$ No original: "we feel sorry because we cry, angry because we strike, afraid because we tremble, and [it is] not that we cry, strike, or tremble, because we are sorry, angry, or fearful, as the case may be" [James, 1884]
} 
É importante ressaltar que o ponto principal da teoria apresentada por James encontra-se na definição de uma emoção unicamente pelo conjunto de alterações físicas percebidas. Esta hipótese recebeu diversas críticas ao longo dos anos, em geral por meio de contraexemplos descrevendo duas ou mais emoções como responsáveis pelo mesmo conjunto de alterações fisiológicas e cuja diferenciação dá-se usualmente graças a termos de contexto. Um exemplo restrito é [Ekman et al, 1976], no qual os autores descrevem a ocorrência de expressões semelhantes para diferentes emoções. Já [Schacter et al, 1962] relata resultados de um experimento envolvendo voluntários foram sujeitos a injeções de adrenalina como estimulante do sistema simpático. Os pesquisadores reportam que os voluntários tendiam a interpretar a experiência como raiva ou euforia, dependendo do tipo de situação à qual eram expostos.

Tais argumentos direcionaram à conclusão de que estados fisiológicos não fornecem princípios para a identificação única de emoções, ainda que, em alguns casos, seus indicadores possam fornecer pistas facilmente associáveis com alguns estados emocionais. Assim, concluiu-se que a diferenciação de emoções específicas deveria residir em camadas além da fisiologia.

Pesquisas recentes utilizando-se de ferramental computacional para diagnóstico de atividade neural como [Mühlberger et al, 2011] ou mesmo [Panksepp, 1998], porém, demonstraram alguma verdade por trás da "hipótese fisiológica". Segundo [de Sousa, 2010], traços fisiológicos podem indicar corretamente um grupo de emoções correlatas, mas para a diferenciação entre culpa, vergonha e embaraço, por exemplo, seria necessário ir além destas informações.

Outro argumento comumente utilizado contra as teorias sentimentalistas é sua incapacidade de explicar a possibilidade de racionalização de emoções, como, por exemplo, a felicidade sentida por receber um presente inesperado. Embora haja emoções advindas de fatos brutos, aquelas que se manifestam no cotidiano são usualmente racionalizáveis.

Por fim, o movimento mais recente dentro das teorias sentimentalistas é apresentado por [Damásio, 1996], que introduz o conceito de marcadores somáticos de forma que, para Damásio, o corpo seja capaz de relacionar a realidade a experiências do passado e experiências hipotéticas futuras, de forma a 
estabelecer um mecanismo operacional, anterior à razão, pelo qual emoções relacionadas a conceitos, expectativas e ausências possam ser entendidas.

\subsubsection{Abordagens Psicológicas}

A aceitação de que emoções possuem objetos formais distanciam estas da interpretação das teorias sentimentalistas e as leva à hipótese central das abordagens psicológicas e evolucionistas: emoções envolvem avaliações ${ }^{6}$ pessoais. Foi Magna Arnold, em 1960, [apud. de Sousa, 2010], quem introduziu o conceito de avaliações na psicologia moderna, caracterizando-o como o processo por meio do qual o significado de uma situação para um indivíduo é determinado ${ }^{7}$.

Klaus Scherer e seu grupo apresentam evidências a favor destes por meio de modelos multimodais, compreendendo 18 ou mais níveis de avaliação, os quais permitem classificar de maneira confiável as emoções experimentadas, [Scherer, 2001] e [Sander et al, 2005].

Tal trabalho baseia-se fortemente nas hipóteses e resultados de Scherer, que define emoções como "[emoções são] um episódio de mudanças interrelacionadas e sincronizadas dos estados na maioria ou em todos os cinco subsistemas do organismo em resposta à avaliação de um estímulo interno ou externo que se mostre relevante às maiores preocupações de tal organismo" 8 , [Scherer, 2001]. Assim, cabe às teorias de avaliação, appraisal theories, o papel de realizar uma abordagem funcional às emoções, de forma que estas passam a ser explicadas como reações cuja função principal é lidar com situações dotadas de significado ao indivíduo.

Naturalmente, a abordagem funcional é compartilhada pelas teorias que analisam as emoções de um ponto de vista evolucionista, as quais frequentemente definem emoções como adaptações cujo propósito é solucionar

\footnotetext{
${ }^{6}$ Ao longo deste trabalho o termo "avaliações" é usado indiscriminadamente como tradução para os conceitos de "evaluation" e "appraisal" uma vez que ambos, nesse contexto, referemse ao mesmo fenômeno.

${ }^{7}$ No original: "... characterizing it [appraisal] as the process through which the significance of a situation for an individual is determined".

${ }^{8}$ No original: "[emotions are] an episode of interrelated, synchronized changes in the states of all or most of the five organismic subsystems in response to the evaluation of an external or internal stimulus event as relevant to major concerns of the organism".
} 
problemas ecológicos básicos que afetam os organismos, como exemplo em [Frank, 1988].

As ideias evolucionistas apresentadas por Darwin foram ponto central para os desenvolvimentos realizados por Tomkins, Izard, Friesen e Ekman, [Ekman, 1992]. Tais pesquisadores, assumindo a hipótese darwiniana, buscaram evidências da universalidade da expressão das emoções em seres humanos. Suas descobertas, resultados e teses são analisados no item 2.2.

As iniciativas em abordagens psicológicas e evolucionistas sobre o tema, porém, ainda falham em responder diversas perguntas, em especial relativas a emoções mais específicas ou racionalizadas por lógicas de ordem superior [de Sousa, 2010]. Emoções como ciúmes, inveja, saudades ou, no extremo, Schadenfreud, não são explicáveis pelas abordagens aqui relacionadas. Ekman et al, [1969], contudo, sustenta a tese de que tais fenômenos não sejam classificados como emoções, resguardando tal substantivo apenas ao conjunto básico. Em [Ortony et al, 1990] é apresentado o fato que a divisão do problema em emoções fundamentais não necessariamente colabora com os estudos da área e sustenta-se a tese de que tal divisão seja, em realidade, uma falácia. $\mathrm{Na}$ publicação, os pesquisadores apontam os diversos conjuntos de emoções relacionados como básicos por cada trabalho como evidência de que a definição encontra-se no método e no propósito da pesquisa e não em características intrínsecas do fenômeno que permitam classificá-lo como básico. Sobretudo, os pesquisadores concluem que assim como os linguistas não buscam definir um grupo de linguagens básicas das quais as demais derivam - ainda que 0 consenso na área seja de que as linguagens modernas compartilham antepassados comuns a partir dos quais se diferenciaram e evoluíram - aqueles envolvidos na pesquisa sobre emoções não deveriam focar na obtenção de um conjunto primário.

\subsubsection{Teorias Cognitivas}

Segundo de Sousa [2010], atualmente a maior parte das teorias sobre emoções pode ser classificada como cognitiva. $O$ autor as distingue das teorias de avalição em função da distinção entre cognição e avaliação (appraisal): enquanto nas teorias de avaliação assume-se que os processos cognitivos relaci- 
onados à avaliação podem ser conscientes ou inconscientes, envolvendo ou não conteúdo proposicional, as teorias cognitivas tipicamente argumentam que emoções envolvem atitudes proposicionais. Assim, exemplifica, alguém não pode estar nervoso com outra pessoa a menos que acredite que esta seja culpada de alguma ofensa. Proponentes de teorias cognitivas defendem que, para caracterizar uma emoção, o sujeito deve sempre ter uma espécie de atitude física, comportamental, hipotética, psicológica ou de outra maneira - em relação à proposição.

De certa forma esta é uma retomada à interpretação Estoica: emoções são crenças oriundas de julgamentos. Esse é o ponto proposto por estudiosos como Roberto Solomon, Jerome Neu e Martha Nussbaum, [apud de Sousa, 2010]. Outras análises introduzem novos elementos, como sentimentos, expectativas, desejos e julgamentos imparciais.

Críticas à visão cognitivista são comuns. Talvez a mais significativa seja a de Deigh, [1994] que evidencia que o caráter proposicional das emoções excluiria seres não dotados de linguagem, como infantes e animais. Outros argumentam que se emoções sempre envolverem as atitudes proposicionais padrão, ou seja, desejos e crenças, então a racionalidade das emoções está reduzida à racionalidade destas atitudes. Outra crítica relaciona-se com a diferença entre estados mentais transientes e duradouros, como, por exemplo, a incapacidade de diferenciar a raiva instantânea de quando alguém destrói sua propriedade e uma contínua propensão à raiva, [Wollheim, 2000].

\subsubsection{Teorias de Percepção}

Um quinto grupo de teorias sobre emoções é denominado "teorias de percepção". Assim, segundo a ótica proposta nestas teorias, as emoções poderiam comportar-se como uma extensão sensorial, consistindo implicitamente de um mecanismo de avaliação entre a mente e o mundo. É importante frisar que tal interpretação permite que emoções ainda sejam entendidas não somente como atos passivos, dependentes de estímulos externos, mas que, assim como o desejo faz o homem ansiar por elementos que não existem e proporciona a sensação de concretização quando alinhamos o mundo às nossas vontades, as emoções podem estruturar-se como percepções internas. 
Na realidade, estendendo essa linha de raciocínio, [de Sousa, 1990] propõe que emoções são percepções da mesma maneira que diferentes pontos de vista, ou seja, espécies de padrões que se salientam entre objetos de foco e atenção, linhas de raciocínio e inferências. Assim, segundo o autor, as emoções seriam responsáveis por ressaltar diferentes aspectos de nossas experiências e seriam, portanto, capazes de agir sobre os mecanismos de atenção, avaliação e compreensão.

Essa afirmação não traça uma linha direta entre emoção, crenças e desejos, mas explica como ela pode influenciá-los, assim como também responde às diversas tentativas dos cognitivistas quanto a agrupar estes três conceitos. Nesse sentido, porém, emoções podem ser entendidas como julgamentos, uma vez que se passa a enxergar e entender o mundo através dos valores associados a elas.

\subsection{Modelos Emocionais}

Ao longo da história do estudo e das teorias sobre emoções diversos modelos foram propostos. Tais modelos possuem em geral, um foco introspectivo, isto é, concentram-se no processo de avaliação, elicitação e percepção das emoções do próprio indivíduo. Esse posicionamento implica, por vezes, em uma complexidade além daquela que será adotada no modelo proposto neste trabalho. Entretanto, uma vez que a concepção da proposta originou-se de tais estudos, é necessária uma rápida análise.

Em primeiro lugar, há a diferenciação entre modelos emocionais discretos e contínuos. Enquanto os primeiros preocupam-se em agrupar rótulos semelhantes sob uma categoria emocional, os modelos contínuos visam também descrever a relação entre tais categorias.

Assim, a

Figura 1 traz, por exemplo, o modelo discreto proposto por Goleman [apud Martinez-Miranda et al, 2005], precursor das ideias sobre inteligência emocional. Tais modelos possibilitam, em suma, a redução do domínio léxico necessário ao entendimento, classificação e pesquisas relacionadas a estados emocionais. Sendo assim, são ferramentas utilizadas em testes interculturais. 
Anger: Fury, outrage, resentment, wrath, exasperation, indignation, vexation, acrimony, animosity, annoyance, irritability, hostility, and at the extreme, pathological hatred and violence.

Sadness: Grief, sorrow, tirelessness, gloom, melancholy, self-pity, loneliness, dejection, despair, and when pathological, severe depression.

Fear: Anxiety, apprehension, nervousness, concern, consternation, misgiving, wariness, qualm, edginess, dread fright, terror; as a psychopathology, phobia and panic.

Enjoyment: Happiness, joy, relief, contentment, bliss, amusement, pride, sensual pleasure, thrill, rapture, gratification, satisfaction, euphoria, whimsy, ecstasy, and at the far edge, mania.

Love: Acceptance, friendliness, trust, kindness, affinity, devotion, adoration and infatuation.

Surprise: Shock, astonishment and amazement.

Disgust: Contempt, disdain, scorn, abhorrence, aversion, distaste and revulsion.

Shame: Guilt, embarrassment, chagrin, remorse, humiliation, regret, mortification and contribution.

Figura 1: Categorias de Emoções Propostas por Goleman, [apud Martinez-Miranda et al, 2005]9

Por sua vez, modelos contínuos buscam, em geral, mapear as categorias emocionais em planos ou campos relacionais. A Figura 2 é um exemplo, referido como "Campo AV", Arousal-Valence, ou Excitação-Significância.

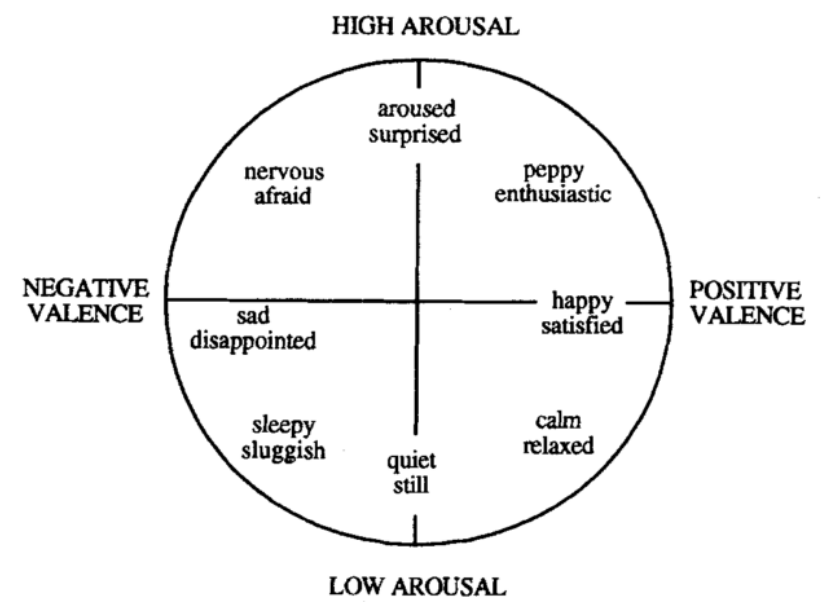

Figura 2: Campo AV extraído de [Feldman, 1993] 9

\footnotetext{
${ }^{9}$ Uma vez que a tradução dos rótulos relacionados aos estados emocionais não necessariamente engloba todos os sentidos do termo original, em Inglês, a figura foi mantida em seu idioma original.
} 
Diversos outros modelos discretos e contínuos, em geral bidimensionais, existem na literatura, mas sua análise foge ao escopo deste trabalho. Uma revisão é realizada por [Laros \& Steenkamp, 2005].

Uma vez que tais modelos versam sobre o mesmo domínio, as questões sobre a equivalência de estados e escalas de conversão surgem naturalmente. Uma primeira abordagem poderia concentrar-se no campo semântico: assim a categoria "Anger" do modelo de Goleman poderia ser mapeada no segundo quadrante do campo proposto por Feldman ("Nervous"), é necessário apontar que, embora os significados sejam próximos, ambos os termos diferem. Por exemplo: um aluno, ao aguardar um teste, pode estar "Nervous" em decorrência da ansiedade sem apresentar-se em um estado "Anger". Além disso, outras categorias, "Love", por exemplo, não possuem qualquer tipo de associação semântica no modelo de Feldman.

Paralelamente à inexistência de uma teoria unificada de emoção, ou até mesmo em decorrência deste fato, não existe na literatura um modelo unificado. A fim de compreender os mecanismos das respostas e transições emocionais, porém, outras duas classes de modelos também são utilizadas.

A primeira delas compreende modelos comportamentais como o exemplo de [Zeeman, 1976], interpretado em [Sander et al, 2005], sobre a resposta do tipo "atacar ou fugir", mostrado na Figura 3.
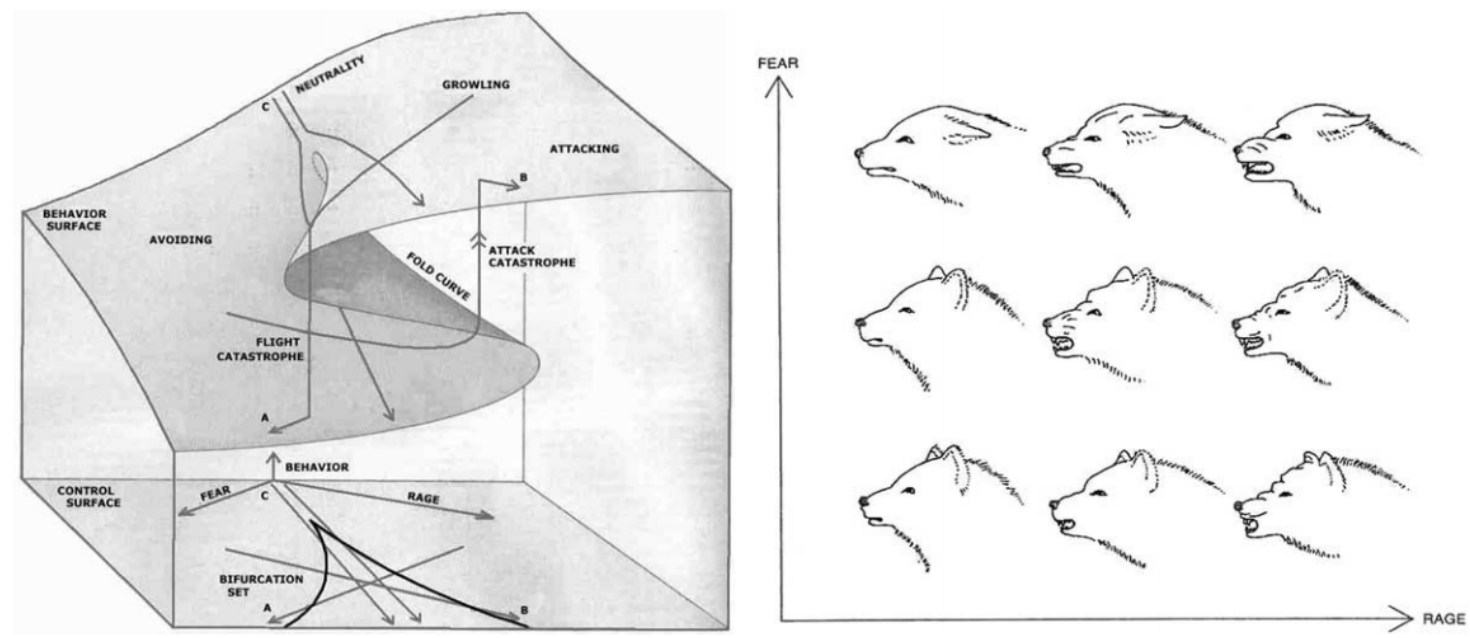

Figura 3: Modelo de resposta para "atacar ou fugir". À esquerda a superfície que modela o comportamento para tal situação, à direita as expressões associadas no comportamento de um lobo. Extraído de [Sander et al, 2005]. 
Tal categoria de modelos lida usualmente com situações comportamentais específicas, como no exemplo. É interessante mencionar a topologia matemática utilizada, uma superfície derivada da teoria das catástrofes.

Assim, esteja o lobo em um estado neutro, indicado pelo ponto C. Seu comportamento diante de um estímulo usualmente percorre as trajetórias diretas até a região de ataque ou de fuga. Há casos, porém, onde o lobo encontrase, por exemplo, encurralado e, apesar do comportamento esperado de fuga, ele parte para $\mathrm{o}$ ataque. Tal comportamento é descrito pela curva que vai até $\mathrm{o}$ ponto A, denominada "Attack Catastrophe". Da mesma forma, o modelo contempla o caso de fuga repentina, "Flight Catastrophe", em que o lobo inicialmente demonstra sinais de hostilidade, como a ação de rosnar, mas subitamente opta pela fuga quando confrontado. Ambos os comportamentos são explicados pela região de dobra, que projeta uma região instável no plano MedoRaiva.

O modelo topológico é entendido ao representarmos o comportamento do lobo por uma partícula deslizando livremente pela superfície. Ao entrar na região catastrófica do domínio - área dentro da região $A B C$ no plano ou porção invertida da superfície - a partícula, entretanto, é instantaneamente transportada para o outro lado.

Alinhado à escola comportamentalista da psicologia, o exemplo de Zeeman utiliza-se das expressões do animal para realizar uma indução sobre seu estado emocional e, logo, prever seu comportamento. A concepção de uma partícula capaz de movimentar-se sobre uma superfície qualquer relacionando o comportamento observado ao estado emocional é central no modelo proposto, como será abordado no capítulo 3 .

Os modelos mais recentes, porém, enquadram-se na categoria cognitiva, compartilhando fortemente das propostas advindas das teorias de avaliação (appraisal theories). Uma vez que se concentram especialmente nos processos internos de elicitação de respostas emocionais a partir da avaliação de eventos, tais modelos possuem pouca aplicação ao tema deste trabalho. Análises destes modelos podem ser encontradas em [Sander et al, 2005], [Scherer, 2001] e [Lazarus, 2001]. 


\subsection{Expressões Faciais}

Seres humanos e a maior parte dos mamíferos utilizam expressões faciais para demonstrar estados emocionais. Um cão mostrando os dentes quando nervoso ou o sorriso de um ser humano para demonstrar felicidade são apenas dois exemplos de situações do cotidiano. Segundo [de Sousa, 2010], a expressão e a compreensão de emoções por meio da face é uma hipótese aceita desde os filósofos gregos. Entretanto, o tema passa a ser foco de estudos científicos aprofundados - isto é, envolvendo aspectos antropológicos e psicológicos sob uma ótica empírica - a partir da segunda metade do século $X X$, com os trabalhos de Tomkins, Izard e Ekman.

Em seu discurso de premiação na APA (American Psychologists Association), em 1992, Paul Ekman diz: "Em 1965 quando eu comecei a estudar expressões faciais poucos acreditavam que havia muito a se aprender. Goldstein apontava que diversos psicólogos famosos - F. e G Allport, Brunswik, Hull, Lindzey, Maslow, Osgood, Tichner - fizeram apenas um estudo facial, os quais não Ihes serviram para ganhar sua reputação. [...] A face era considerada uma fonte ruim de informações imprecisas, culturalmente específicas e estereotipadas." ${ }^{10}$, [Ekman, 1992]. O próprio Ekman aponta ainda que a contradição entre a visão da psicologia e a experiência cotidiana, a qual inclui as expressões faciais como parte significativa e confiável da comunicação não verbal, o motivou a aprofundar-se nesse campo, propondo e realizando estudos interculturais.

A utilização de uma normativa comum de denominação e identificação das atuações faciais foi central para o desenvolvimento das pesquisas em identificação de expressões faciais, aponta [Rosenfeld, 2000]. Embora a tentativa original de normatizar uma taxonomia para a área pertença a [lzard, 1971], o sistema de codificação de atuação facial, FACS (Facial Action Coding System), de Ekman e Friesen, [Ekman el al, 1978], representa o padrão de facto nos es-

\footnotetext{
${ }^{10}$ No original: "In 1965 when I began to study facial expression, few thought there was much to be learned. Goldstein pointed out that a number of famous psychologists - F. and G Allport, Brunswik, Hull, Lindzey, Maslow, Osgood, Tichner — did only one facial study, which was not what earned them their reputations. [...] The face was considered a meager source of mostly inaccurate, culture-specific, stereotypical information."
} 
tudos desde então, como ressaltam [Pantic el al, 2000B], [Fasel, 2002], [Essa, 1997] e o próprio [Rosenfeld, 2000].

O sistema FACS define uma série de unidades de ação, action units (AUs), para a descrição funcional das expressões faciais, as quais [Fasel, 2002] define sob uma ótica fisiológica como usualmente produzidas a partir de contrações da musculatura da face e que implicam em deformações temporárias nas regiões de interesse do rosto, como sobrancelhas, pálpebras, nariz, lábios e na textura da pele, usualmente reveladas por meio de dobras e rugas. O trabalho de Ekman e Friesen, [Ekman el al, 1978], pode ser compreendido como uma camada de abstração à atuação muscular subjacente à ocorrência de determinada expressão, uma vez que, por meio da identificação das AUs correspondentes é possível relacionar a musculatura envolvida.

O FACS define, por exemplo, que a expressão involuntária e sincera de felicidade como a atuação das AUs número 6 e 12, ou seja, o levantar das bochechas e a extensão lateral e vertical dos lábios, respectivamente. Uma expressão forçada demonstra apenas atuação da AU 12. A diferenciação é possível uma vez que a AU 12, a qual representa a contração do músculo zigomático maior, é voluntária, enquanto a AU 6 , contração do músculo orbicular do olho, ocorre involuntariamente.

Além disso, o FACS traz considerações sobre a duração e a intensidade das unidades de ação. Atuações musculares espontâneas estão compreendidas na faixa $250 \mathrm{~ms}$ a $5 \mathrm{~s}$, dependendo da AU, [Fasel et al, 2003]. Já as regras para a determinação da intensidade de cada AU são apresentadas como, por exemplo, o grau de elevação do canto dos lábios para a AU 12, ou a densidade de rugas sobre o nariz, AU 44, a qual é naturalmente exibida em uma expressão de raiva. Experimentos e técnicas para a observação, catalogação e medição das atividades relacionadas aos AUs são discutidos em [Ekman, 1982].

É importante ressaltar o consenso sobre a dificuldade de determinar a intensidade da demonstração dos AUs em uma escala absoluta, conforme destacado por [Ekman, 1978], [Essa, 1994], [Black, 1997], [Pantic et al, 2000B], [Fasel, 2002], [Valstar, 2011]. Desta maneira, escalas relativas, nas quais as regiões de interesse são comparadas às exibidas em uma face neutra, são 
empregadas explicita ou implicitamente por estes autores. A determinação da face neutra pode, ainda, ser representativa de um conjunto de indivíduos, caracterizando uma expressão geral, ou de um indivíduo específico. As instruções de avaliação de expressões faciais do FACS recomendam que os avaliadores iniciem com uma representação de caso geral e, à medida que interagem com um indivíduo específico, assumam uma escala ajustada especificamente. Em teoria, um mecanismo de aprendizado contínuo permitiria a um sistema computacional realizar o mesmo procedimento.

Segundo [Pantic et al, 2000B], uma vez que o FACS é o padrão de facto para a análise objetiva de expressões faciais, a automação da detecção e classificação das unidades de ação proporcionaria a ampliação de sua aplicação nas ciências comportamentais, as quais são, em última análise, a base das interfaces multimodais. Este entendimento, por parte da comunidade científica, convergiu em uma série de métodos, como os em [Chuang, 2006], [Donato et al, 1999], [Bartlett et al, 1999], [Essa et al, 1994], [Pantic et al, 2000A], [Tian et al, 2001], [Cohn et al, 1997] e [Lien et al, 1998].

Ekman e Friesen demonstraram evidências a favor da hipótese de universalidade das expressões faciais emocionais em estudos interculturais com populações iletradas da Papua-Nova-Guiné e investigaram a influência de fenômenos culturais, [Ekman et al, 1969]. Propuseram, ainda, a hipótese de regras de demonstração ${ }^{11}$, as quais explicam a influência do comportamento social no que diz respeito a demonstrar ou não determinada expressão. Outros trabalhos apontaram que a correspondência entre a emoção expressada na expressão facial e a compreensão humana era ainda maior quando os voluntários podiam descrever a emoção exibida em suas próprias palavras [Izard, 1971].

Tais estudos e experimentos correlatos demonstraram que as expressões faciais que indicam emoções podem ser classificadas, com taxas de erro inferiores àquelas de um classificador aleatório, mesmo em casos interculturais e por observadores não treinados. Todavia, os dados empíricos não são prova suficiente para a confirmação tese da universalidade.

\footnotetext{
${ }^{11}$ As regras de demonstração são tratadas nos trabalhos originais como "display rules" e explicam a influência da situação na forma de demonstração da emoção através da expressão facial.
} 
Não por acaso, os trabalhos em defesa de tal tese receberam críticas diversas de antropologistas, como revisado em [Lutz et al, 1986]. Mais do que isso, diversas críticas, demonstra [Russell, 1994], são embasadas em argumentos psicológicos, uma vez que a hipótese da universalidade possui implicações profundas na área. Universais ou não, as expressões faciais são aceitas em consenso como portadoras de semântica emocional.

\subsection{Técnicas Computacionais}

Ao longo dos últimos anos, com a popularização dos sistemas de detecção de faces devida, em grande parte, ao algoritmo adaptativo de ViolaJones, [Viola et al, 2004] e [Jones et al, 2003], e também dos trabalhos de Paul Ekman, os sistemas de detecção de expressões faciais vêm se popularizando. Utilizados em dispositivos eletrônicos, catalogação de imagens em bancos de dados de redes sociais e aplicativos de computadores, tais sistemas foram introduzidos no cotidiano da vida digital. Enquanto isso, a automação do processo de identificação de expressões faciais, bem como de sua interpretação semântica, é objeto de aplicação de diversas técnicas de visão computacional e inteligência artificial, [Fasel et al, 2003].

Nesse sentido, o objetivo desta seção é apresentar um breve levantamento das abordagens recentes sobre o tema, oferecendo uma análise histórica e comparativa. Para tanto, [Pantic et al, 2000] e [Fasel et al, 2003] propõem analisar os principais componentes da cadeia de processamento de dados, isto é, os sistemas de detecção facial, de extração dos dados faciais e de classificação da expressão. A Figura 4 apresenta a cadeia de processamento conforme o entendimento de [Fasel et al, 2003]. 


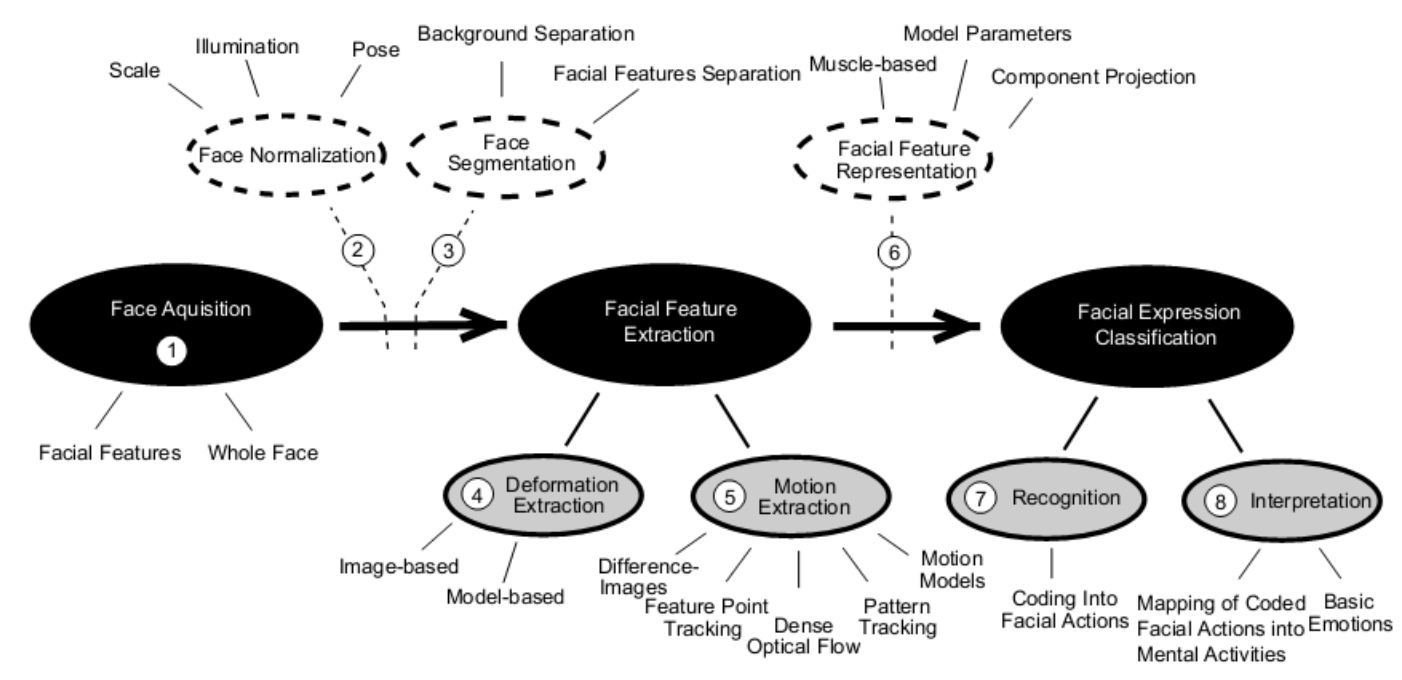

Figura 4: Cadeia de processamento de dados em sistemas de classificação de expressões faciais, [Fasel et al, 2003].

É possível observar que o autor divide a cadeia de processamento de dados em três fases principais: a aquisição da face, na qual o sistema de classificação detecta a face na imagem ou sequência de vídeo de entrada; a extração dos elementos faciais relevantes, na qual o sistema extrai automaticamente os parâmetros que serão utilizados no classificador; a classificação da expressão. O autor indica etapas de apoio, como a normalização ou segmentação das faces, em balões tracejados. Os balões cinza são utilizados para destacar etapas independentes em cada uma das fases principais. Por fim, algumas das diferentes técnicas possíveis para uma etapa ou fase são listadas.

Após a identificação das expressões faciais, outro algoritmo de classificação ou inferência deve ser utilizado para extrair um significado semântico a partir de uma série de expressões. Tal significado pode envolver estados mentais ou emocionais, abordados em categorias amplas ou restritas. A Seção 2.4.3 apresenta alguns trabalhos sobre o tema.

\subsubsection{Detecção Facial}

Um sistema automatizado de detecção de faces, em sua forma ideal, possui a capacidade de detectar corretamente a presença de uma ou mais faces em uma imagem ou sequência de vídeo, independentemente da complexi- 
dade da cena, [Fasel et al, 2003], e condições de distorção e pose da face, [Pantic et al, 2000].

O algoritmo de Viola-Jones, [Viola et al, 2004] e [Jones et al, 2003] tornou-se o padrão de facto para a detecção de faces em imagens arbitrárias [Zhang et al, 2010]. Ele utiliza uma série de elementos de Haar retangulares, os quais são comparados com a imagem em diferentes escalas e orientações. Com base na detecção destes elementos, os autores propõem um classificador monolítico, isto é, que avalia o grau de aceitação de cada um dos elementos e infere a classificação a partir do conjunto de medidas como um todo, e também um classificador em cascata, no qual o segmento de imagem pode ser descartado em fases intermediárias do processamento, conforme a Figura 5.

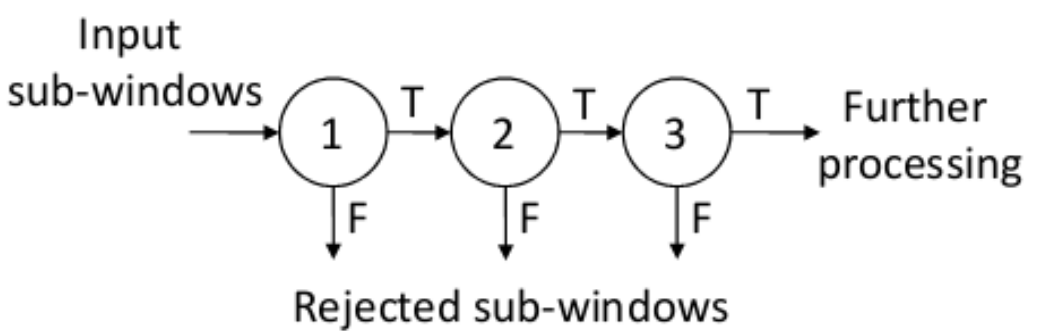

Figura 5: Classificadores em cascata. Segmentos que não contêm faces são rejeitados no início do processamento, diminuindo o custo computacional, [Viola et al, 2004].

A utilização dos classificadores em cascata permite a eliminação antecipada de segmentos da imagem que não sejam considerados bons candidatos a possuir faces. Desta forma, apenas um número reduzido de candidatos procede até as últimas etapas da cascata de processamento, reduzindo o custo computacional da detecção. Comparado ao classificador monolítico, [Viola et al, 2004] descreve a classificação em cascata como uma árvore de decisão deteriorada. O desempenho de ambos é comparado na Figura 6. 


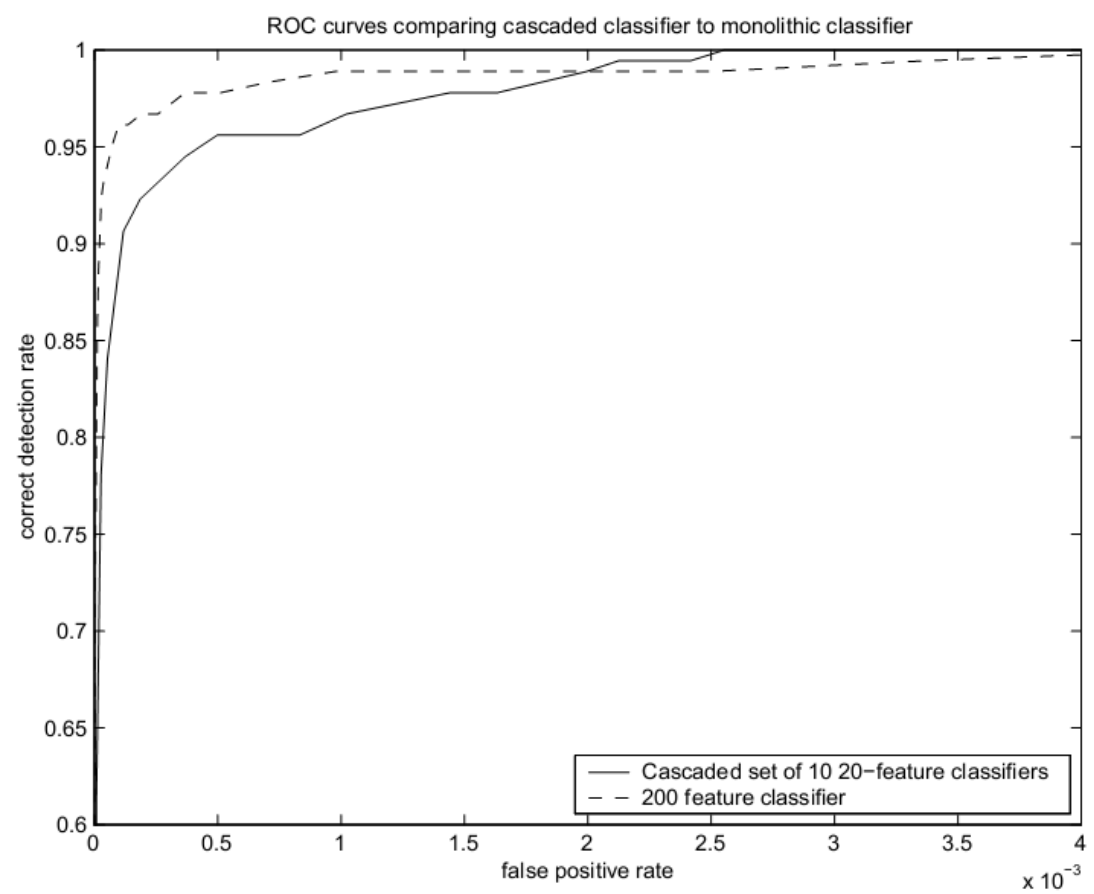

Figura 6: Relação entre índice de detecção e taxa de falsos positivos para um classificador monolítico e um classificador em cascata [Viola et al, 2004].

A Figura 6 exibe duas séries de dados, relativas a um classificador monolítico, linha tracejada, ou a um conjunto a um classificador em cascata, linha contínua. Ainda assim, o sistema em cascata apresenta redução de uma ordem de grandeza no custo computacional de execução do algoritmo, o que levou a sua adoção em diversas aplicações de detecção facial em tempo real.

Em razão do baixo custo computacional, baixa taxa de falsos positivos, o modelo de [Viola et al, 2004] recebeu atenção comercial e acadêmica ao longo dos últimos anos; dentre os desenvolvimentos incrementais listam-se novos modelos de aprendizado de máquina, novos elementos de comparação e diferentes estratégias para o sequenciamento dos classificadores, [Zhang et al, 2010].

O levantamento de [Zhang et al, 2010] afirma ainda que o cenário de pesquisas em detecção facial apresenta avanços utilizando outras técnicas, como redes neurais, redes bayesianas, máquinas de vetores de suporte (SVM) e estratégias de detecção de elementos faciais. Técnicas de eliminação antecipada aplicadas aos algoritmos baseados em SVM têm possibilitado uma alter- 
nativa interessante ao algoritmo de Viola-Jones, tanto em termos de custo computacional quanto de desempenho.

Segundo [Pantic et al, 2000], os sistemas atuais, entretanto, apresentam limitações, dentre as quais condições de posição e orientação da face (referidos conjuntamente como "pose"), de iluminação, de complexidade da cena e da existência de oclusões aparecem de maneira recorrente como dificuldades na execução desta tarefa.

Os problemas de pose são oriundos das diferentes aparências da face em razão da distância e do ângulo na qual é observada. Enquanto a distância induz apenas distorções na escala e no nível de detalhes da imagem, a variação angular da face na forma de movimento de rotação angular em torno dos eixos contidos no plano de imagem incorre em distorções das características faciais e até mesmo possíveis oclusões [Essa et al, 1994].

Um exemplo deste fato pode ser visualizado ao comparar uma face em vista frontal e uma vista de perfil, isto é, rotacionada de noventa graus em torno do eixo vertical contido no plano da imagem. No primeiro caso é possível observar ambos os olhos e a ação da musculatura em ambos os lados da face, já a imagem de perfil fornece somente parte desta informação.

Diferentes condições de iluminação também podem ser responsáveis pela alteração na forma em que as faces são percebidas e registradas na forma de imagens, em especial nos casos onde há influência não uniforme de múltiplas fontes sobre a mesma face. Outro fator limitante é, por vezes, a complexidade da cena na qual as faces encontram-se inseridas, a que pode levar a falsos positivos ou falsos negativos.

Por fim, as oclusões, situações na qual a face é parcialmente ocultada, podem levar à impossibilidade de detecção de uma face. Tal situação é comumente causada pela presença de corpos rígidos sobrepostos à face, tais como óculos, mãos e chapéus e também em situações relacionadas à presença de barba, bigode, cabelos ou outros corpos não rígidos.

\subsubsection{Extração de Elementos Faciais e Classificação de Expressões}

Após a delimitação das faces, é necessário identificar e extrair os elementos faciais que serão utilizados na etapa de classificação de expressões 
faciais. Em [Pantic et al, 2000A] a autora divide estes subsistemas em dois grupos: métodos detecção de padrões e métodos baseados em características $^{12}$.

Os métodos de detecção de padrões são aqueles em que um modelo, como um grafo, uma superfície de Bézier, uma malha tridimensional ou outro modelo parametrizável a ser comparado com a imagem a ser analisada. $O$ classificador, localizado na próxima etapa de processamento, recebe uma série de valores identificando o grau de correspondência entre o padrão analisado e a imagem facial.

Os métodos baseados em características, por sua vez, acompanham elementos faciais, identificando seu estado e acompanhando sua evolução dinâmica quando o objeto de estudo é uma sequência de vídeo.

O aplicativo comercial eMotion, [Sebe et al, 2007], por exemplo, utilizase de uma malha tridimensional deformável a qual é, durante a inicialização, manualmente ajustada sobre o rosto. A malha acompanha as deformações faciais e os parâmetros que governam tal deformação são enviados, quadro a quadro, para o sistema de classificação. A Figura 7 é um exemplo desta malha; é possível visualizar sua disposição especialmente densa em torno das regiões ocular e labial, as quais são usualmente associadas às expressões faciais de caráter emocional [Ekman et al, 1978].

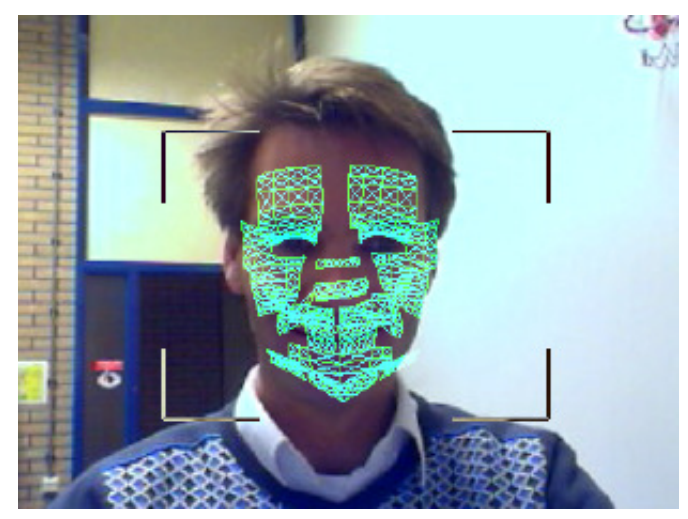

Figura 7: Malha de extração de elementos faciais utilizada pelo software eMotion.

Uma classificação mais recente e detalhada das estratégias e algoritmos de extração de elementos faciais é apresentada em [Fasel et al, 2003].

\footnotetext{
${ }^{12}$ NT: No original, "template matching methods" e "feature based methods".
} 
Inicialmente, os autores separam tais elementos em permanentes e transientes. O primeiro grupo inclui olhos, boca, nariz, sobrancelhas e características que estão sempre presentes na face e cuja deformação, movimento ou outra característica de estado são o objeto de análise. O segundo grupo, por sua vez, inclui rugas, variações locais de textura e quaisquer outros elementos que podem surgir e desaparecer durante uma sequência de vídeo.

O levantamento também separa as abordagens entre aquelas baseadas em deformação, isto é, na comparação entre a face a ser analisada e um modelo ou amostra de face neutra, e as baseadas em movimento, nas quais a movimentação da face ou de elementos dela constitui a base de parâmetros de interesse. O primeiro grupo é constituído por técnicas capazes de analisar imagens estáticas ou sequências de vídeo - em geral utilizando a análise quadro a quadro -, já o segundo grupo é formado por técnicas capazes de analisar apenas vídeos.

Técnicas de extração de deformação podem ser holísticas ou locais, isto é, podem interpretar a face como um todo - um processo realizado, por exemplo, por meio de ondaletas (wavelets) de Gabor - ou serem aplicadas separadamente às regiões faciais de interesse. A extração do movimento, por sua vez, é normalmente realizada por meio do processamento do fluxo ótico, para o qual também é possível empregar análises globais ou locais. A Figura 8 e a Figura 9 exemplificam a extração de deformação e de movimento, respectivamente.

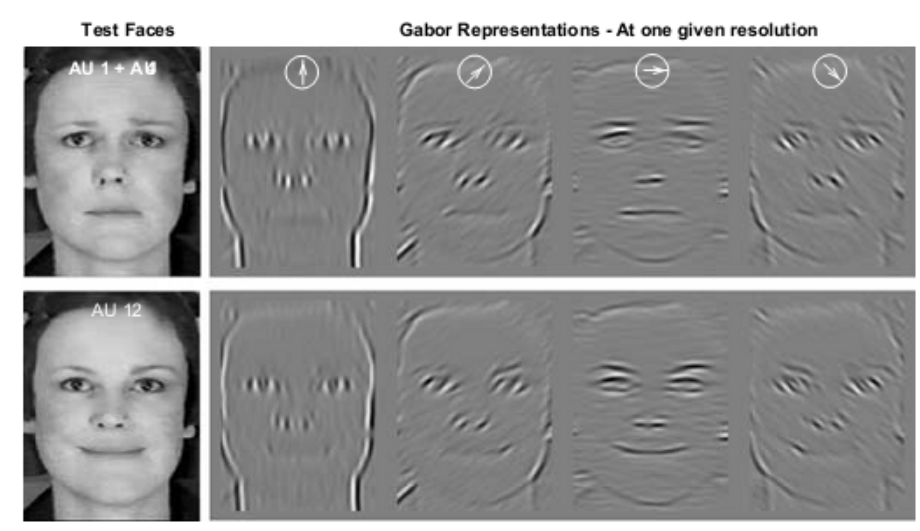

Figura 8: Extração de deformação por meio de ondaletas de Gabor, [Fasel et al, 2003]. 


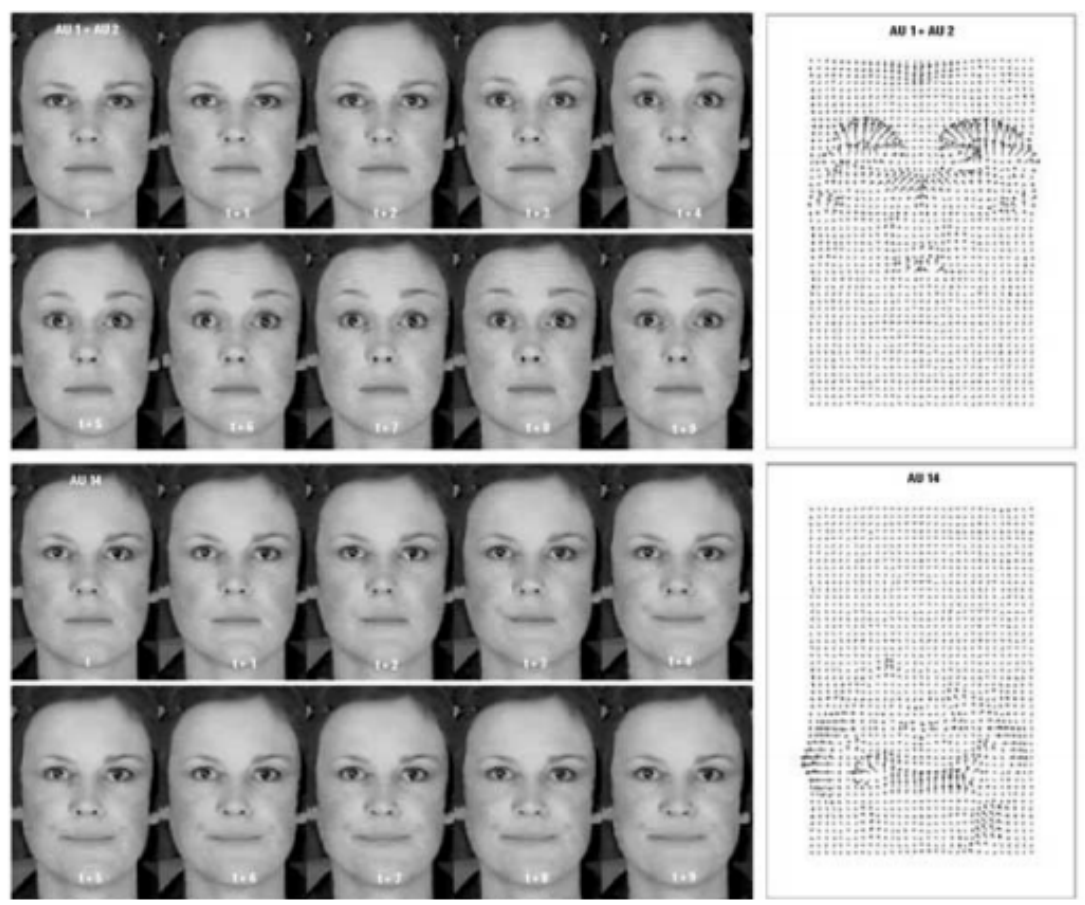

Figura 9: Extração de movimento por meio de técnicas de fluxo ótico, [Fasel et al, 2003]. Destaca-se a assimetria acentuada na movimentação da região inferior da face no segundo caso de análise.

Os mecanismos de extração de elementos faciais podem também ser diferenciados com respeito ao processamento direto da imagem ou à utilização de um modelo ajustado à face, propõe [Fasel et al, 2003]. Enquanto a primeira abordagem resulta, usualmente, em técnicas mais diretas e de menor custo computacional, seu desempenho é comumente degradado em função de problemas de estimação de pose. As técnicas de ajuste de modelo são indicadas para a reconstrução dos estados da face em virtude de diversas observações simultânea. Seu exemplo mais direto é a estimação de uma malha tridimensional a partir de diversas câmeras, todavia modelos bidimensionais ou baseados em um único observador também existem.

A última diferenciação feita por [Fasel et al, 2003] é sobre a extração de elementos com base na aparência ou com base na reconstrução da atividade muscular. A primeira opção é mais comumente empregada em sistemas de identificação de expressões faciais, já a segunda requer técnicas indiretas de medição do estado muscular e é normalmente empregada na animação de faces sintetizadas. 
A etapa final dos algoritmos de detecção de expressões faciais é a classificação dos dados obtidos a fim de identificar e interpretar a expressão detectada. Independente das categorias de interesse, [Pantic et al, 2000A], afirma que os sistemas de classificação podem ser baseados em regras, padrões, ou redes neurais. Uma abordagem mais moderna permite a generalização das redes neurais em classificadores que possuam uma fase de treinamento.

Sistemas de regras podem ser entendidos de forma geral como sistemas especialistas nos quais um conjunto de regras pré-definido é aplicado para a classificação dos elementos. As regras codificadas em termos de expressão de unidades de ação do FACS, [Ekman et al, 1978] são utilizadas como conhecimento especialista em [Barlett, 1996], [Pantic et al, 2000B], [Fasel et al, 2000], [Cohn et al, 1997], [Lien el al, 1998].

Durante um processo de classificação baseado em padrões, os elementos de interesse extraídos na fase anterior são comparados a padrões definidos para cada uma das categorias possíveis. A revisão de [Pantic et al, 2000] destaca um obstáculo oriundo da existência de infinitas expressões faciais possíveis, as quais devem, necessariamente ser representadas por um conjunto finito de padrões. Além disso, ressalta, as diferenças interpessoais quanto à intensidade da expressão tornam o desafio mais complexo.

Os classificadores que possuem uma fase de treinamento permitem o aprendizado automático dos padrões relacionados a cada uma das categorias de interesse. Em geral um conjunto de amostras previamente classificadas é utilizado para o ajuste dos parâmetros internos do classificador por meio de um mecanismo de retroalimentação. Escolhas comuns são redes-neurais, redes bayesianas e máquinas de suporte de suporte de vetores.

\subsubsection{Inferência de Estados Emocionais}

O desenvolvimento recente das interfaces homem-máquina estendeu o paradigma tradicional para além dos manetes, do teclado e do mouse. Sistemas comerciais modernos são capazes de processar comandos de voz e gestuais; todavia a inferência do estado emocional do usuário ainda é um assunto restrito a pesquisas e modelos acadêmicos. 
Neste sentido, Piccard [2001] destaca a importância da compreensão emocional. Segundo a autora, o relacionamento entre o homem e a máquina vem tornando-se progressivamente natural e social. Desta forma, à medida que as interfaces evoluem, elas enfrentam as mesmas expectativas presentes no relacionamento interpessoal. Quando tais expectativas não são correspondidas, o usuário pode vir a sentir-se frustrado.

Nass e Reeves [apud Piccard, 2001] realizaram experimentos nas situações de interação tipicamente interpessoal são reproduzidas na forma de interação homem-máquina. Os pesquisadores concluem que os resultados básicos se mantêm: por exemplo, uma situação na qual um dispositivo apenas fala com o usuário, mas nunca o escuta, elícita uma resposta emocional condizente à mesma situação quando o dispositivo é substituído por um interlocutor.

Piccard [2001] conjectura ainda a respeito de um sistema sociável adaptativo onde um algoritmo de aprendizado de máquina seria continuamente utilizado para determinar o momento mais oportuno para interromper o interlocutor durante um diálogo. Tal sistema teria a capacidade de aprender com base na percepção da reação emocional do usuário, de maneira similar à dos seres humanos. A autora argumenta que um sistema computacional não deve limitar-se à análise de expressões faciais e de vocalização, mas sim coletar dados relacionados à resposta fisiológica, como a velocidade de respiração, alterações na resposta galvânica da pele e variações no ritmo cardíaco e vaiáveis de contexto.

De fato, pesquisas recentes sobre a inferência de estados emocionais são usualmente multissensoriais. Uma destas pesquisas, realizada pela Microsoft, [LiKamWa et al, 2011], propõe inferir o estado emocional do usuário a partir de parâmetros de contexto extraídos da utilização de smartphones, tais como o perfil de utilização de SMS, de chamadas e de acesso à internet, e as localidades visitadas pelo usuário. A oportunidade de informar seu próprio estado emocional é oferecida ao usuário por meio do "MoodSense", um aplicativo desenvolvido para este fim. Os dados coletados pelo aplicativo permitem a construção de um modelo de inferência personalizado para cada um dos usuários.Os resultados apresentados em [LiKamWa et al, 2011] são de uma taxa global de $61 \%$ sucesso na inferência utilizando o modelo genérico, quando 
comparado à informação fornecida por meio do "MoodSense". Os modelos personalizados permitem uma melhora significativa no desempenho, levando 0 desempenho médio a $91 \%$ quando considerados os 25 participantes do teste. Os pesquisadores destacam ainda que, neste segundo cenário, os resultados encontram-se dento da faixa de $77 \%$ a $98 \%$ de sucesso.

A janela de tempo utilizada em [LiKamWa et al, 2011] é de três dias, o que permite destacar a característica temporal desta espécie de aplicações. Sistemas de inferência emocional devem analisar janelas de dados suficientemente longas para a detecção de alterações emocionais de interesse. Assim, sistemas utilizados para a detecção de alterações ao longo de um diálogo, por exemplo, possuem estados de interesse e uma janela de análise diferentes daqueles como o de [LiKamWa et al, 2011]. A questão do janelamento é abordada na Figura 10.
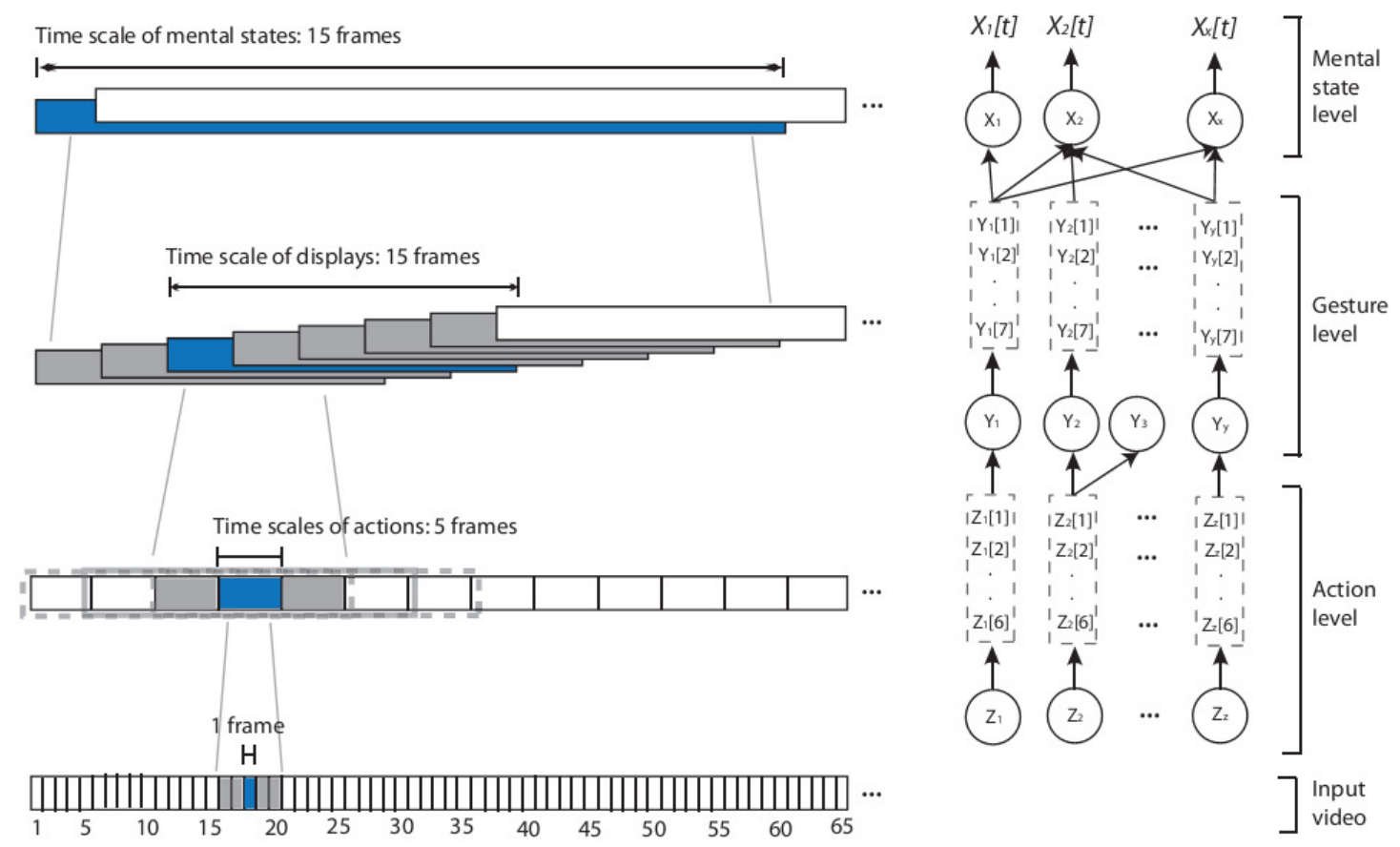

Figura 10: Problema de janelamento na análise de estados emocionais [Baltrusaitis, 2011].

Na parte inferior direita da Figura 10 é possível observar a menor unidade de percepção em um sistema de análise visual comum, o quadro de vídeo. Para a análise gestual do torso superior e das expressões faciais, [Baltru- 
saitis, 2011] trabalha com uma janela de 5 quadros, ou cerca de $200 \mathrm{~ms}$, o que permite detectar ações como um sorriso ou o encolher dos ombros. O sistema utiliza janelas sobrepostas de quinze quadros para detectar o que os autores chamam de estados mentais, como raiva, medo, alegria, tristeza, alívio, interesse, incerteza, concentração e se o interlocutor está ou não concordando com a mensagem transmitida.

O sistema de inferência proposto em [Baltrusaitis, 2011] utiliza modelos ocultos de Markov (HMM) para detectar expressões, a partir de unidades de ação, e gestos emocionais. Em seguida, utiliza-se uma rede Bayesiana para determinar a probabilidade de cada um dos estados mentais, decidindo-se pelo estado mais provável como classificação para determinada amostra.

Em contraste com os múltiplos estados mentais observáveis no trabaIho de Baltrusaitis, [Kapoor, 2007] apresenta um sistema projetado para detectar e prever frustração, com foco em ambientes de aprendizado. A redução do escopo de aplicação do sistema permite a utilização de sensores dedicados ao cenário. A arquitetura do experimento compreende uma cadeira instrumentada com sensores de pressão, assim como o mouse. O usuário utiliza uma pulseira com eletrodos para detectar a condutividade da pele e duas câmeras, uma para detecção de atividade facial e outra para um aspecto mais geral do comportamento. A acurácia do sistema, empregando um classificador de processo Gaussiano, foi de $79,17 \%$ no experimento com 24 sujeitos, de ambos os sexos.

Em [Abbasi et al, 2009] é proposto um sistema de inferência do estado mental a partir de expressões de linguagem corporal. Assim, observam-se os gestos inconscientes de estudantes durante uma atividade típica de aula. A Figura 11 demonstra a rede Bayesiana utilizada para obter informação semântica a partir das observações. 


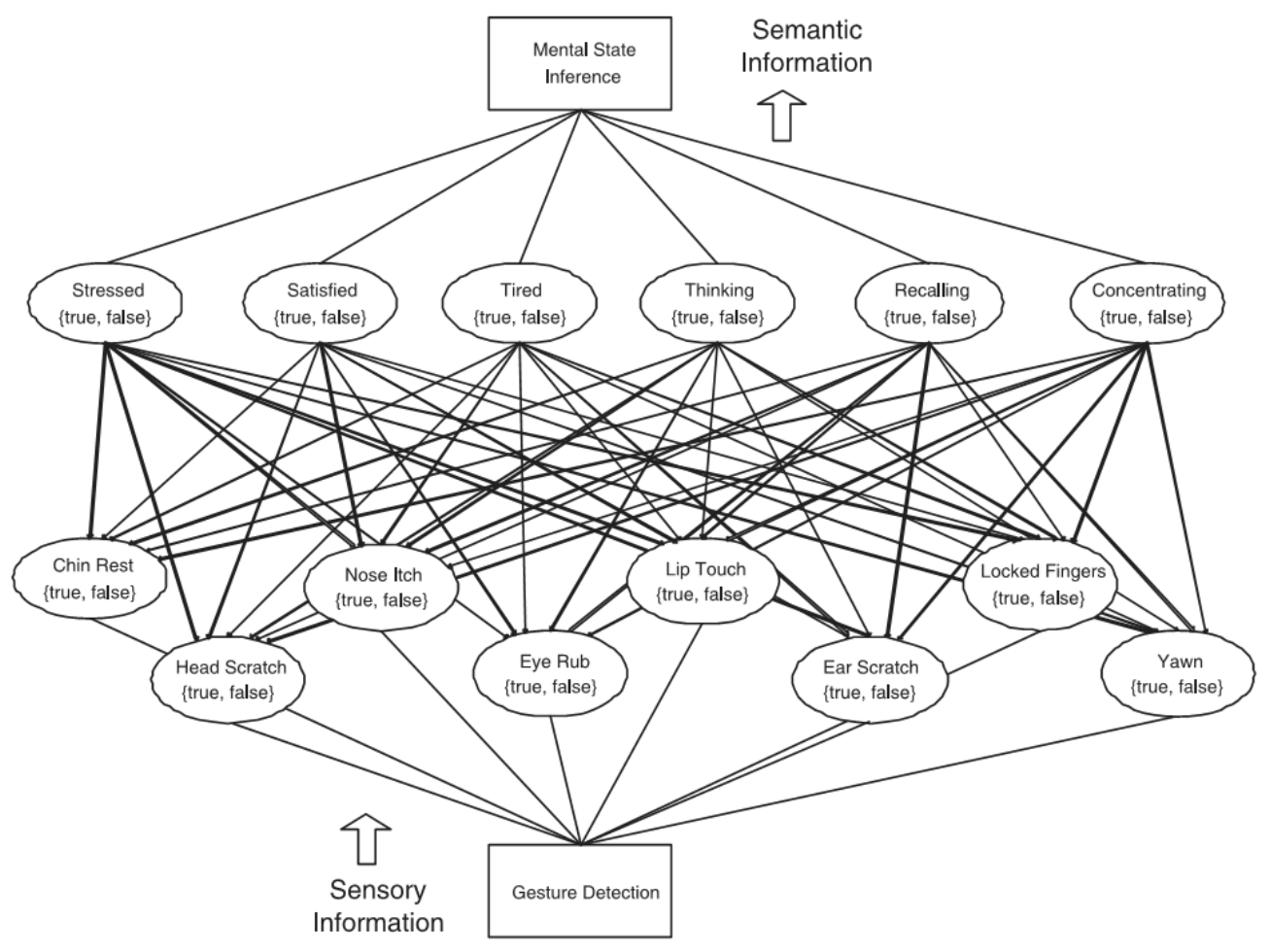

Figura 11: Rede Bayesiana utilizada para inferência de estados mentais de alunos durante uma aula, com base em sua linguagem corporal [Abbasi et al, 2009] .

A rede Bayesiana apresentada na Figura 11 permite a inferência de probabilidades para cada um dos estados do modelo, apresentados na parte superior da imagem, a partir da detecção dos gestos idiomáticos presentes na região inferior. O sistema proposto não possui meios automáticos para o reconhecimento dos gestos, os quais foram identificados manualmente em onze sequências de vídeo, com base na análise de trechos de vinte segundos.

O modelo proposto em [Abbasi et al, 2009] recebe atenção especial devido à aplicação de um rede Bayesiana dinâmica $(D B M)$, utilizando um modelo oculto de Markov (HMM) para a transição de estados. Os pesquisadores afirmam que tal modelo permite caracterizar a natureza dinâmica do processo, incluindo as dependências temporais das transições dos estados mentais do processo. A Figura 12 destaca o processo de evolução de estados e observação de expressões corporais. 


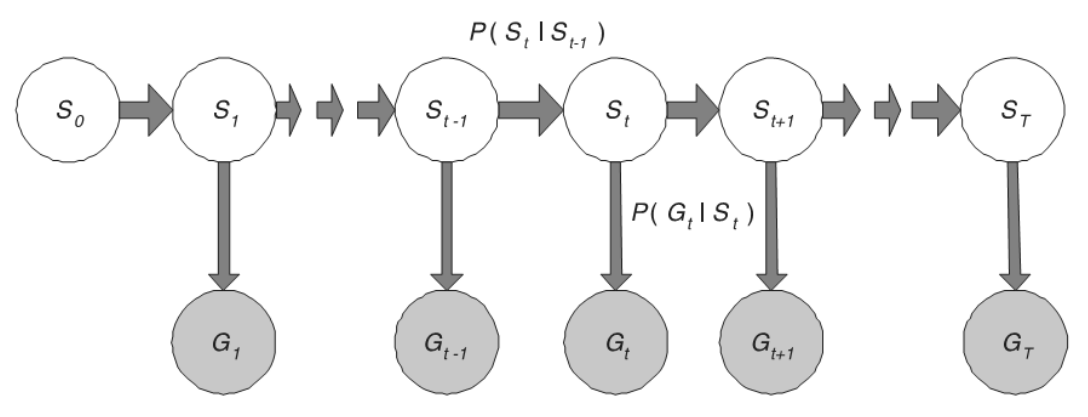

Figura 12: Transições de estados mentais e observações sensoriais [Abbasi et al, 2009].

$\mathrm{Na}$ Figura 12 os nós acinzentados correspondem a observações de expressões corporais, as quais podem ou não estar presente em uma dada janela de 20 segundos. Os nós sem preenchimento denotam os diferentes estados mentais modelados, os quais não são diretamente observáveis e devem ser, portanto, inferidos. Para cada janela de tempo, o sistema utiliza uma etapa de evolução de estados e, quando há informação sensorial disponível, uma etapa de incorporação de novas observações.

A avaliação dos resultados de [Abbasi et al, 2009] é realizada por meio da comparação dos estados estimados com aqueles relatados pelos participantes do experimento durante uma sessão na qual são instruídos a assistir o próprio vídeo complementando-o com anotações de como se sentiam. A classificação obtida possui $97,4 \%$ de precisão quando o modelo inclui a categoria "Neutro" e $83.2 \%$ quando esta categoria é suprimida. Os experimentos demonstraram que, de forma geral, em contextos específicos, as expressões gestuais podem ser utilizadas para elevar a efetividade de atividades, tais como lecionar.

Durante o estudo, os pesquisadores observaram um resultado descrito como "provocativo" [Abbasi et al, 2009]. Os participantes do experimento não foram capazes de lembrar de qualquer estado mental em particular enquanto assistiam o próprio vídeo, ao menos que visualizassem dicas provindas de seus próprios gestos.

Uma possível explicação seria que o participante poderia ter classificado seu estado mental com base nas imagens, isto é, abordando a situação de maneira que se em um dado momento ele exprimiu um gesto característico 
de um estado mental então ele estaria naquele estado. Uma segunda possibilidade seria de que, ao ver-se realizando determinados gestos, o sujeito estaria revivendo os estados mentais pelos quais passou naquele momento. Esta última interpretação retoma a afirmação de Damásio [apud Abbasi et al, 2009] de que "para sentir uma emoção é necessário mas não suficiente que os sinais neurais das vísceras, músculos, juntas e dos núcleos neurotransmissores todos os quais são ativados durante o processo de uma emoção - atinjam um certo núcleo subcortical e o córtex cerebral”. Estímulo visual pode ativar a repetição mental de determinadas atuações motoras, levando ao sentimento da emoção em si ou à entrada no estado mental correspondente. 


\section{Capítulo 3: Modelo Proposto}

Este capítulo apresenta a contribuição do presente trabalho: um modelo matemático para a inferência do estado emocional por meio do pósprocessamento dos dados fornecidos por detectores de expressões faciais.

\subsection{Visão Geral}

O modelo proposto permite a estimação do estado emocional do interlocutor por meio da cadeia de processamento apresentada na Figura 13.

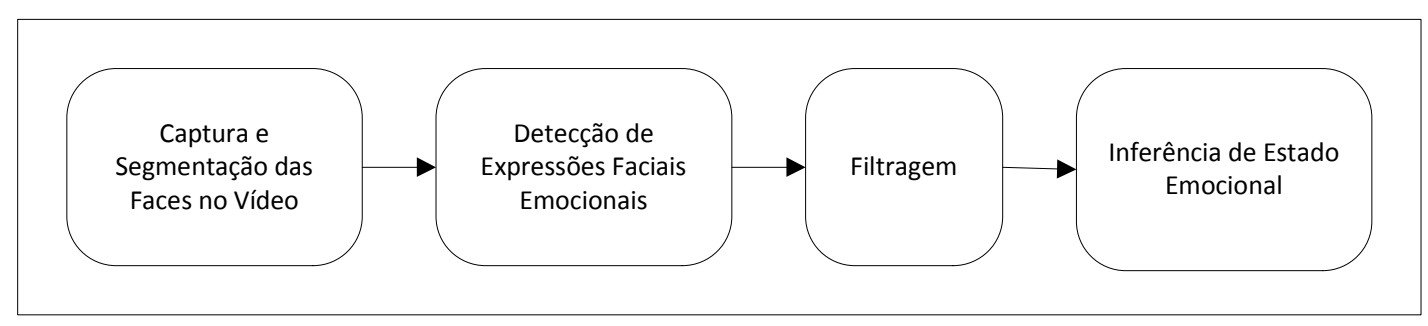

Figura 13: Pipeline de processamento de dados

A captura e segmentação das faces no vídeo são realizadas a priori, com marcações manuais conforme requeridas pelo algoritmo ou aplicativo de identificação de expressões.

O modelo proposto é agnóstico à tecnologia utilizada nesta etapa. $\mathrm{O}$ algoritmo escolhido para a detecção de expressões faciais emocionais deverá fornecer uma sequência ordenada de observações com a probabilidade de detecção de cada uma das emoções. Alternativas comerciais adequadas no momento da elaboração deste trabalho são o eMotion [Sebe et al, 2007] e o Fraunhofer FaceDetect [Ernst et al, 2009].

Em seguida o sinal relativo a cada uma das emoções é processado separadamente em um algoritmo de filtragem de sinais, o qual considera a dinâmica das expressões faciais em questão, a taxa de amostragem do vídeo e as incertezas associadas ao modelo subjacente ao filtro e à aquisição do sinal.

Por fim os sinais filtrados são utilizados na etapa de inferência emocional, na qual uma partícula movimenta-se sobre uma superfície contínua, a qual tem por função modelar as emoções representadas e suas transições. As 
mudanças no vetor de velocidade da partícula são função das probabilidades de detecção de expressões faciais associadas a cada uma das emoções, da topologia desta superfície e da posição da partícula quando da detecção de uma nova expressão facial. O estado emocional em um determinado instante poder ser obtido, portanto, diretamente a partir da leitura da posição da partícula.

Este capítulo detalha as etapas de filtragem de sinais e de inferência emocional. Por fim, é apresentada uma heurística automatizada para a determinação dos parâmetros de filtragem. Tal heurística é acessória e possibilita a adaptação do modelo ao algoritmo de aquisição e identificação de expressões.

\subsection{Captura de Vídeo e Detecção de Expressões Faciais}

Os processos de captura de vídeo e de detecção de expressões faciais emocionais do pipeline de processamento apresentado são realizados por subsistemas capazes de exportar os dados de suas observações. Ainda que o modelo seja agnóstico quanto ao subsistema escolhido, espera-se que esta forneça à etapa de filtragem de sinal os seguintes dados:

- Número da observação;

- Número do quadro (frame) do vídeo em que a observação foi realizada;

- Crença na detecção de expressão emocional em cada um das consideradas.

Um exemplo ilustrativo e válido é apresentado no Excerto de Código 1:

\begin{tabular}{|rrrrrr|}
\hline \# Observação & Quadro & Felicidade & Raiva & Medo & Tristeza \\
41 & 10832 & 0.000 & 0.004 & 0.050 & 0.916 \\
42 & 11096 & 0.000 & 0.008 & 0.019 & 0.940 \\
43 & 11359 & 0.000 & 0.010 & 0.005 & 0.049 \\
44 & 11624 & 0.000 & 0.016 & 0.006 & 0.019 \\
45 & 11888 & 0.128 & 0.001 & 0.871 & 0.000 \\
46 & 12151 & 0.035 & 0.005 & 0.940 & 0.019 \\
\hline
\end{tabular}

Excerto de Código 1: Saída do detector de expressões faciais eMotion 
Para demonstrar a necessidade de filtragem dos sinais, considere 0 vídeo de expressões de raiva. A Figura 14 apresenta algumas cenas e a Figura 15 são os gráficos associados a este vídeo para Felicidade, Tristeza, Medo e Raiva.
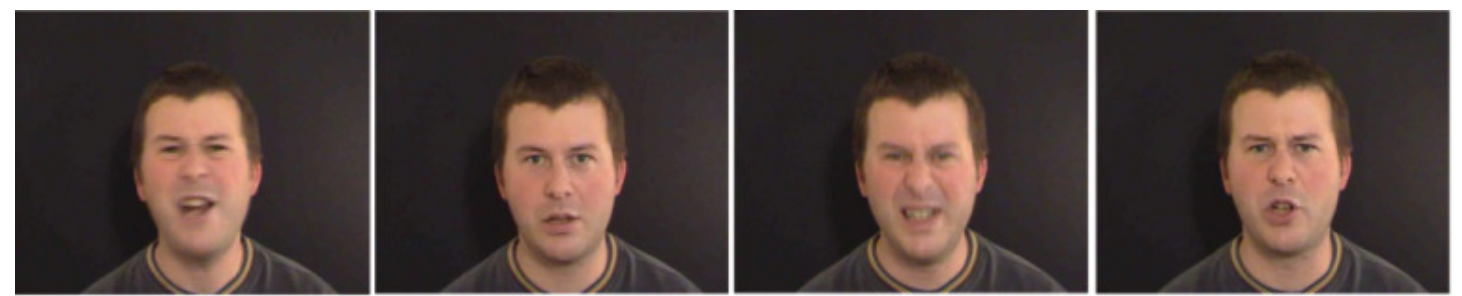

Figura 14: Imagens do vídeo ilustrativo. As imagens, da esquerda para a direita, foram classificadas pelo eMotion como felicidade $(100 \%$ de certeza, aos $2,36 \mathrm{~s})$, tristeza $(70,6 \%$, $0,76 \mathrm{~s})$, medo $(83,1 \%, 3,92 \mathrm{~s})$ e raiva $(76 \%, 3,04 \mathrm{~s})$.
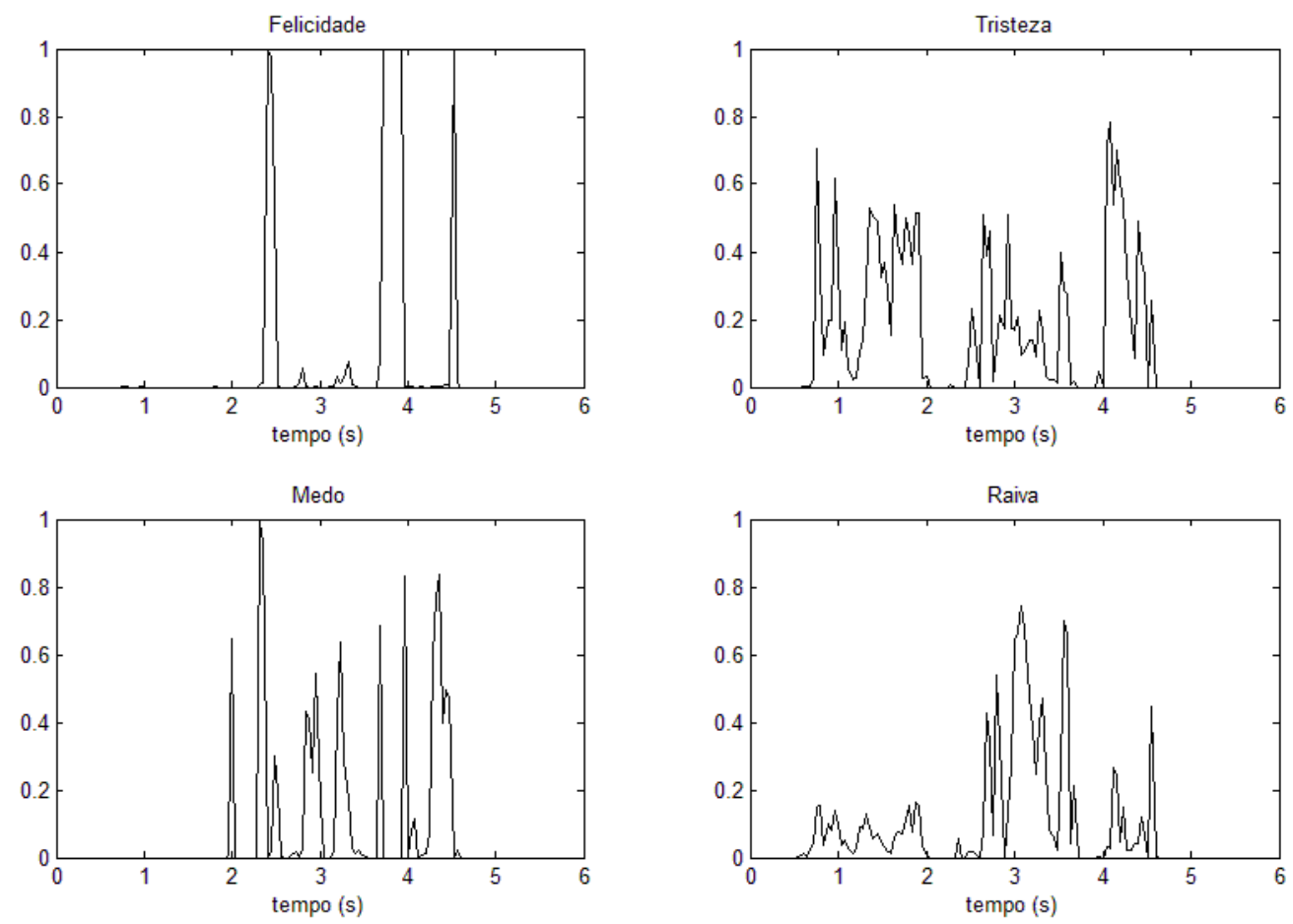

Figura 15: Saídas do eMotion para o vídeo ilustrativo.

É possível observar que há uma discrepância entre a análise do aplicativo e a expressão do ator para os quatro instantes selecionados acima.

A julgar apenas pela assinatura de cada um dos gráficos um observador poderia concluir pela classificação deste vídeo como representante majoritário de tristeza, ao invés de optar pela classificação correta, raiva, a qual se encontra tão evidente no vídeo quanto na Figura 14: Imagens do vídeo ilustrativo. As imagens, da esquerda para a direita, foram classificadas pelo eMotion 
como felicidade ( $100 \%$ de certeza, aos $2,36 \mathrm{~s})$, tristeza $(70,6 \%, 0,76 \mathrm{~s})$, medo $(83,1 \%, 3,92 \mathrm{~s})$ e raiva $(76 \%, 3,04 \mathrm{~s})$.

Outro fato importante a ser observado é que ainda que a taxa de amostragem do vídeo seja adequada à detecção contínua do movimento e das expressões faciais, os sinais obtidos ao fim da análise são inerentemente descontínuos.

Detectores de expressão facial são baseados em algoritmos originalmente desenvolvidos para a análise de imagens estáticas ou segmentos muito curtos de vídeo, de forma que nenhum dos dois aplicativos possui internamente um modelo capaz de incorporar as nuances da mecânica facial. Assim, ao analisar os vídeos como uma sequência de quadros estáticos, tais algoritmos perdem as informações relativas à continuidade do movimento e dos estados. $\mathrm{Na}$ próxima sessão, filtros de Kalman independentes serão utilizados paralelamente para o pré-processamento destes sinais.

\subsection{Filtragem do Sinal}

Após a identificação de expressões faciais, obtêm-se valores estimados para a ocorrência de cada uma das expressões associadas às emoções de interesse.

A análise de vídeos multimodais realísticos deve lidar com diversas fontes de ruído, seja no processo ou na própria observação. Movimentos faciais associados à fala são exemplos de ruídos de processo, enquanto variações de luz podem ser consideradas como ruídos de medição. Fenômenos como estes, ao lado de características específicas do sistema de captura de imagens, movimentos da cabeça, oclusões, mau posicionamento da malha, entre outros, tornam os dados intrinsicamente ruidosos.

Em busca de um filtro probabilístico capaz de estimar os estados com base nas medições fornecidas por tais aplicativos, o modelo proposto recorre à utilização de filtros de Kalman para cada uma das emoções detectadas. Isto é, a série temporal de cada uma das entradas é filtrada separadamente.

Uma vez que as acelerações da musculatura facial não consistem em um estado de interesse e são por vezes indetectáveis tanto ao olho humano 
quanto a câmeras cuja frequência de amostragem situa-se em torno de vinte e cinco quadros por segundo (25 fps), optou-se por sistemas lineares de primeira ordem como modelos subjacentes, os quais garantem que o sinal filtrado seja contínuo.

Mais do que isso, tais sistemas constituem filtros passa-baixas que podem ser ajustados de forma a atenuar os ruídos. Esta escolha de projeto reduz a filtragem a sistemas do tipo SISO (Single-Input/Single-Output) e, portanto, não leva em consideração a influência entre os sinais.

Assim, um sistema linear na forma apresentada nas equações 1 e 2 , bem como as etapas de avanço no tempo, eqs. 2 e 4, e observação de medidas, eqs. 5, 6 e 7, são utilizadas na filtragem de cada uma das séries emocionais obtidas.

$$
\begin{aligned}
& x_{s}=\dot{\mathrm{x}}_{\mathrm{s}} \\
& \mathrm{y}=\frac{\mathrm{Kx}_{\mathrm{s}}}{\tau}
\end{aligned}
$$

Onde:

K é o ganho do sistema;

$\tau$ é a constante de tempo do sistema;

$y$ é a saída do sistema;

$\mathrm{x}_{\mathrm{s}}$ a entrada do sistema.

As equações do filtro de Kalman discreto para tal sistema são escritas como:

\section{Avanço no Tempo}

$$
\begin{gathered}
x_{s, t}=x_{s, t-1} \\
p=p+\frac{w}{\tau^{2}}
\end{gathered}
$$

Onde:

$$
x_{s, t} \text { é o valor de x atual; }
$$


$x_{s, t-1}$ é o valor de $\mathrm{x}$ no instante anterior;

$w$ é a covariância do ruído do processo, $N(0, w)$;

$p$ é covariância de $x_{s, t}, N(0, p)$.

\section{Observação}

$$
\begin{gathered}
m=\frac{\frac{p K}{\tau}}{p\left(\frac{K}{\tau}\right)^{2}+v} \\
x_{s, t}=x_{s . t}+m *\left(r_{t}-y_{t}\right) \\
p=\left(1-\frac{m K}{\tau}\right) * p
\end{gathered}
$$

Onde:

m: Covariância residual;

$v$ : Covariância do ruído de observação, $\mathrm{N}(0, v)$;

$\mathrm{r}_{\mathrm{t}}$ : Medição atual proveniente do aplicativo de detecção de expressões faciais;

$\mathrm{y}_{\mathrm{t}}$ : Saída atual do filtro.

Assim, para cada instante, realiza-se um passo de avanço no tempo, propagando a dinâmica do sistema por meio do modelo linear de primeira ordem implícito. Após este passo, verifica-se se há um quadro analisado para tal instante; caso haja, realiza-se a fase de observação, introduzindo os dados obtidos por meio da análise do vídeo.

É válido ressaltar que, uma vez que a rotina de filtragem tem como objetivo execução em tempo real, processando os dados à medida que chegam, os filtros de Kalman devem resolver a equação de Riccati iterativamente durante a execução. Nessa situação, uma estimativa inicial da variância e do ganho de Kalman é necessária para o início do processo. Seguindo uma prática comum tais estimativas são configuradas como nulas, [Welch et al, 2006].

A aplicação do filtro de Kalman como descrita pressupõe que os ruídos sejam modelados como gaussianos e de média zero, [Welch et al, 2006]. Tais condições foram assumidas devido à complexidade e aparente aleatoriedade 
do movimento facial devido à fala e das pequenas variações de luz nas cenas. $\mathrm{O}$ argumento é construído, portanto, sobre o teorema central do limite. A convergência dos filtros durante os experimentos realizados proporcionaram reafirmação desta hipótese para os casos estudados.

\subsection{Estimação do Estado Emocional}

O modelo proposto para a estimação do estado emocional por meio de uma sequência já filtrada de sinais relacionados à detecção de expressões faciais instantâneas pode ser compreendido por meio da analogia com um sistema mecânico.

Uma partícula desloca-se sobre uma superfície N-dimensional (superfície de dinâmica emocional, SDE) sujeita a mudanças de velocidade proporcionais à probabilidade atual associada a cada emoção. Além disso, sobre a SDE são definidos pontos representativos de cada uma das emoções de interesse. Tais pontos são denominados "atratores".

Suponha que o sistema detecte uma expressão associada à emoção felicidade. Tal evento será aplicado como um aumento na velocidade da partícula em direção ao atrator relacionado. A cada instante, define-se um vetor $\vec{V}_{a}$ para cada atrator, respeitando as seguintes características:

- Originado na posição atual da partícula;

- Orientado em direção ao atrator;

- Tangente à superfície;

- Módulo proporcional ao sinal relacionado ao atrator no instante.

Dessa forma, a velocidade instantânea da partícula pode ser determinada utilizando-se a equação 8 .

$$
\vec{V}_{p}=\vec{V}_{e}+\sum_{a=1}^{N} \vec{V}_{a}
$$

Onde: 
$\vec{V}_{p}$ : Velocidade instantânea da partícula;

$\vec{V}_{e}$ : Velocidade de escorregamento da partícula, paralela ao gradiente da superfície na posição instantânea;

$\vec{V}_{a}$ : Velocidade em direção a cada um dos atratores.

Considere-se, por exemplo, um caso simples onde uma SDE com apenas dois graus de liberdade é utilizada para inferências entre dois estados emocionais detectáveis: felicidade e tristeza.

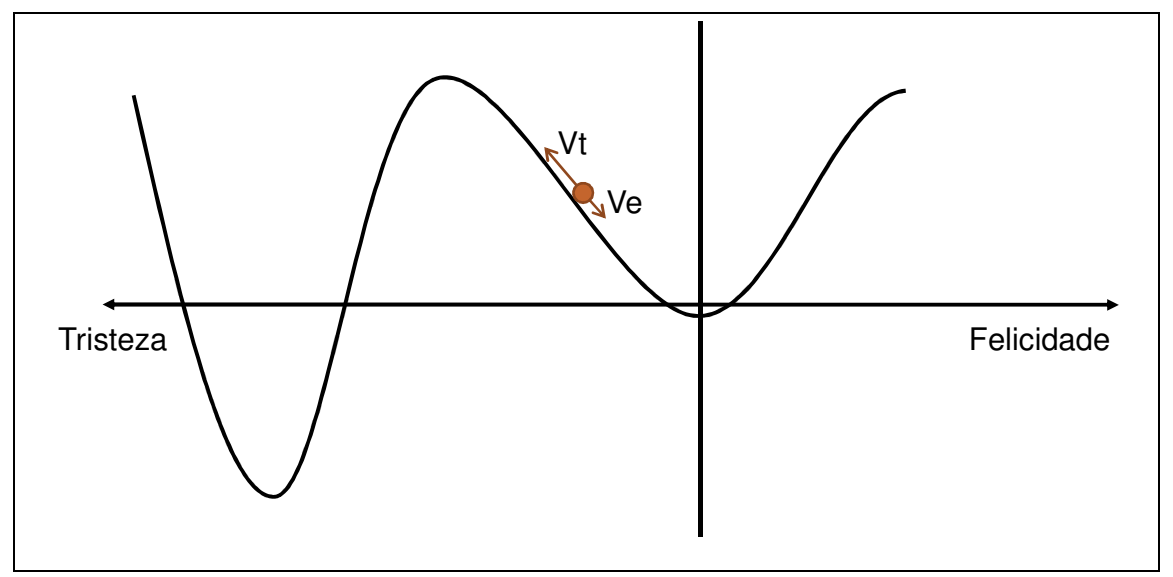

Figura 16: Exemplo de curva de dinâmica emocional

A partícula, portanto, movimenta-se livremente sobre a curva emocional segundo efeitos dos atratores, representados na figura pela velocidade em direção à tristeza, $\mathrm{V}_{t}$, e escorregamento, $\mathrm{V}_{e}$. Os efeitos de atração compreendem a intensidade com a qual a partícula é atraída para as projeções dos atratores na curva, aqui localizados no infinito negativo e positivo do eixo $\mathrm{X}$.

$O$ efeito de escoamento é compreendido como a velocidade com a qual a partícula escoa sobre a curva no sentido de assentá-la em mínimos locais. O modelo mais simples para este tipo de curva deve incluir ao menos um ponto do mínimo, para o qual a partícula será deslocada caso nenhuma atividade emocional seja detectada.

\section{A curva utilizada na}

Figura 16, porém, possui dois pontos de mínimo, sendo um local próximo à origem e equidistante dos atratores, o qual, portanto, pode ser compre- 
endido como neutro e um global mais próximo do atrator de tristeza. Enquanto a partícula se movimenta em torno do mínimo local, ela retornará ao neutro espontaneamente, mas uma vez que ela se aproxime do mínimo global a partícula ficará aprisionada no vale determinado por este, de modo que serão necessárias muitas observações de expressões de felicidade para que ela possa escapar.

Considere-se agora uma SDE tridimensional, capaz de representar um espectro mais amplo de emoções, enriquecendo o modelo de inferência de estado emocional.

Neste caso é possível expressar a SDE de forma geral como:

$$
\gamma(x, y)=(x, y, f(x, y)) .
$$

A velocidade em direção a cada um dos atratores, $\vec{V}_{a}$, pode ser expressa como:

$$
\vec{V}_{a, t}=F_{a, t} * \frac{\nabla \gamma(x, y)}{|\nabla \gamma(x, y)|},
$$

onde:

$F_{a, t}$ : Sinal instantâneo, já filtrado, associado à emoção do atrator, obtido conforme a Equação 2.

A posição da partícula em cada instante pode ser diretamente calculada por meio de um integrador. A determinação do estado emocional em determinado instante será, usualmente, função da posição relativa da partícula em relação aos atratores. A trajetória da partícula sobre a SDE demonstra a melhor inferência possível realizada pelo sistema até aquele instante.

É natural que a SDE apresente diferentes topologias de indivíduo para indivíduo. Ainda assim, argumenta-se que para a maior parte das situações usuais, na ausência de distúrbios psicológicos, o domínio de interesse localiza- 
se próximo à origem e, para tal região, é viável propor uma SDE geral capaz de modelar e inferir qualitativamente o estado emocional.

Da mesma forma, argumenta-se que as diferenças interpessoais a serem modeladas na SDE sejam tão maiores quanto mais distantes da origem o estado emocional encontra-se no campo AV, incluindo a existência de superfícies caóticas como a apresentada para situações de "atacar ou fugir", na Figura 3.

\subsection{Ajuste Automático dos Filtros}

Para a realização das inferências por meio do modelo proposto, é necessário conhecer a priori um conjunto de parâmetros de filtragem, os quais estão relacionados especialmente ao algoritmo escolhido para obtenção dos dados de expressões faciais. Frequência de amostragem, qualidade do ajuste do classificador, metodologia de detecção de padrões escolhida e outros fatores podem impactar qualitativamente e quantitativamente nos dados disponíveis para o modelo.

Uma vez que o ajuste manual de tais parâmetros é complexo, a heurística de simulação-otimização baseada em um algoritmo de recozimento simulado (Simulated Annealing, [Laarhoven, et al, 1992]) é proposta em caráter acessório ao modelo. Procedimentos deste tipo são comumente aplicados para a determinação de um conjunto de parâmetros capaz de minimizar uma função de energia associada ao erro de um classificador. A etapa de simulação utiliza parâmetros estimados pelo processo de otimização para calcular um novo valor para a função de energia com base na análise de um conjunto de vídeos de teste. Após a simulação, a etapa de otimização reavalia os parâmetros e o processo se repete. Para a primeira iteração da etapa de simulação os parâmetros são iniciados com valores aleatórios.

Neste sistema, os vetores de ruído de processo e de observação podem ser definidos agrupando os ruídos associados a cada uma das emoções:

$$
Q_{n}=\left[w_{a 1}, w_{a 2}, \ldots, w_{a n}\right]
$$

onde:

$Q_{n}:$ Vetor de covariâncias dos ruídos de processo; 
$w_{a n}$ : Covariância de processo para o atrator $\mathrm{n}$;

$$
R_{n}=\left[v_{a 1}, v_{a 2}, \ldots, v_{a n}\right],
$$

onde:

$R_{n}$ : Vetor de covariâncias dos ruídos de observação.

$v_{a n}$ : Covariância do ruído de observação para o atrator $\mathrm{n}$

O processo de recozimento simulado utiliza nomenclatura similar à do recozimento de metais, processo tradicional no qual se altera a estrutura cristalina do material por meio do aquecimento e resfriamento controlados; desta forma, parte-se de um estado de alta energia associada ao se escolher uma temperatura inicial elevada e escolhe-se um fator pelo qual essa energia é retirada do sistema. Definimos, portanto:

$$
T_{n+1}=K_{t} * T_{n},
$$

onde:

$T_{n}$ : Temperatura durante a iteração $n$;

$K_{t}$ : Coeficiente de decaimento, $K_{t}<0$.

O processo itera sobre um conjunto de vídeos de aprendizado até que a temperatura do sistema atinja a temperatura ambiente, ponto no qual uma peça sujeita ao recozimento tradicional possui balanço de calor nulo. Dados uma temperatura inicial $\left(T_{0}\right)$ e uma temperatura ambiente $\left(T_{a m b}\right)$, o número de iterações pode ser calculado como:

$$
N_{\text {passos }}=\left(\log _{K_{t}} \frac{T_{0}}{T_{a m b}}\right) .
$$

Para cada vídeo a trajetória da partícula sobre a superfície emocional (trajetória emocional) é dividida em duas metades, do instante inicial até a metade da sequência analisada e deste ponto até o final. 
O processo de treinamento supõe a utilização de vídeos unimodais, ou seja, onde uma das emoções de estudo seja claramente predominante. Para estes vídeos a função de energia $\left(E_{i}\right)$ é então calculada pela quantidade de pontos da segunda metade que se encontram fora de seu setor de classificação nominal. Por exemplo, considere um vídeo de felicidade no qual 100 quadros são analisados. Neste caso, a função de energia pode ser compreendida como o número de estimativas no intervalo de quadros $[51,100]$ que se encontram fora do quadrante relativo à felicidade.

A função de energia global pode ser definida como:

$$
E_{g, n}=\sum_{0}^{N_{\text {videos }}} E_{i, n} .
$$

O sistema então gera parâmetros vizinhos aleatoriamente para os vetores $Q_{n+1}$ e $R_{n+1}$. Após reanalisar os vídeos ele obtém $E_{\text {global, } n+1}$. A probabilidade de aceitar os novos parâmetros como solução é dada pelo critério de Metropolis [Laarhoven et al, 1992]:

$$
P_{\text {aceitação }}=\min \left\{\begin{array}{c}
1, \\
e^{\frac{E_{g, n}-E_{g, n+1}}{T_{n+1}}} .
\end{array}\right.
$$

O algoritmo como um todo é sumarizado conforme apresentado em Algoritmo 1.

\footnotetext{
* Este algoritmo tem como objetivo a determinação dos valores $Q$ e $R$ por meio do processo de * recozimento simulado. São realizadas iterações sobre o conjunto de vídeos de aprendizado

* nas quais um componente aleatório destes vetores é alterado e calcula-se um valor de

* energia global. Os valores selecionados serão aqueles nos quais a função de energia é

* minimizada. O número de iterações é determinado */

Escolher T_0, T_amb, K Calcular N_passos // (Eq. 14) Inicializar os vetores $Q$ e $R$ aleatoriamente $Q$ novo $\leftarrow Q$ $R$ novo $\leftarrow R$ $\mathrm{E} \leftarrow \mathrm{E}$ melhor $\leftarrow \mathrm{MAX}$ INT
} 


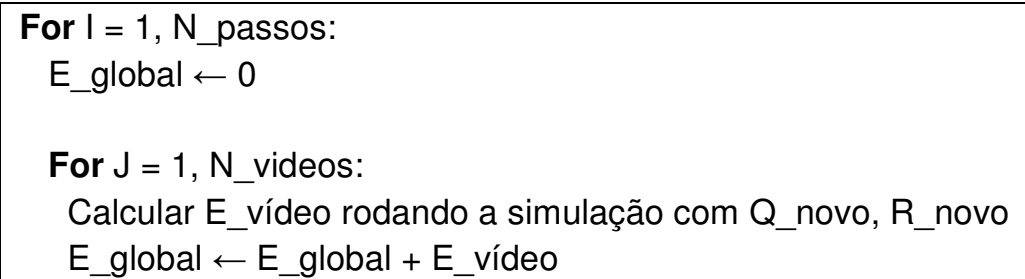

\section{End}

Calcular P_aceitação // (Eq. 16)

If Aleatório $(0,1)<=P$ _aceitação:

$$
\begin{aligned}
& E \leftarrow E \_ \text {global } \\
& Q \leftarrow Q \text { novo } \\
& R \leftarrow R \text { _novo }
\end{aligned}
$$

End

If E_global < E_melhor:

$$
\begin{aligned}
& \text { E_best } \leftarrow \text { E_global } \\
& \text { Q_melhor } \leftarrow Q \text { Qnovo } \\
& \text { R_melhor } \leftarrow R \text { _novo }
\end{aligned}
$$

End

Modificar aleatoriamente um componente de $\mathrm{Q}$ ou $\mathrm{R}$ End

Algoritmo 1: Algoritmo de simulação-otimização para ajuste automático dos parâmetros do filtro.

Cabe destacar que cada iteração implica o processamento de todo o conjunto de vídeos a fim de calcular um novo valor para a função de energia global, $E_{g, n}$. 


\section{Capítulo 4: Validação do Modelo}

\subsection{Visão Geral}

Para avaliar a validade do modelo proposto, bem como sua modularidade, foram realizados experimentos tendo por base apenas a análise de expressões faciais realizada pelo aplicativo comercial eMotion em um corpus direcionado a este campo de pesquisa e disponível gratuitamente.

A seleção de vídeos para o estudo apresenta alguns desafios. Além de condições técnicas mínimas, também é necessário um desempenho razoável por parte do ator em sua tentativa de transmitir a emoção.

Foram selecionados 50 vídeos de um banco de dados de vídeos emocionais multimodais nos quais o autor acreditava que as emoções eram transmitidas de maneira coerente por meio das expressões faciais do interlocutor. Tais vídeos foram exibidos a um grupo de dezessete voluntários, os quais classificaram as emoções expressadas. Com base em dados da literatura, foi possível concluir por um subconjunto de 30 destes vídeos para realização dos testes computacionais.

Os vídeos selecionados foram então analisados utilizando-se um aplicativo comercial e resultaram em 30 arquivos estruturados contendo a análise emocional a cada quadro. Optando-se por um modelo compreendendo apenas raiva, medo, tristeza e felicidade, as informações referentes a estas emoções foram introduzidas no sistema de inferência.

A filtragem foi realizada por meio de um filtro de Kalman após o ajuste automático dos parâmetros do modelo e do filtro. Para tanto se utilizou o recozimento simulado para um conjunto de 16 vídeos de treinamento, o qual corresponde ao emprego de uma estratégia de aprendizado de máquina. Uma vez que a utilização do conjunto de treinamento nas etapas posteriores de treinamento implicaria a obtenção de resultados enviesados, prosseguiram-se apenas com os 14 vídeos restantes.

Os sinais pós-filtragem de tais vídeos foram aplicados à superfície utilizando-se um interpolador de ordem zero e um integrador pelo método de Euler. As trajetórias desenvolvidas pela partícula emocional foram analisadas 
com base em direcionamento e proximidade aos atratores. Finalmente, os resultados obtidos foram comparados com os resultados etiquetados no corpus, bem como à análise feita pelos voluntários.

\subsection{Corpus}

A seleção de vídeos que integram o corpus para a realização de um experimento do modelo proposto é sujeita a requisitos técnicos e semânticos. O primeiro grupo é constituído por características como posicionamento, iluminação e movimentação da face. Tais requisitos advêm, em especial, dos limites impostos pelos aplicativos de detecção computacional de expressões faciais. Em geral, as seguintes condições são impostas.

- Iluminação Frontal: A iluminação, direta ou indireta, deve prover condições equivalentes àquelas de uma iluminação frontal da face, isto é, ser capaz de distribuir luz uniformemente sobre o rosto, evitando sombras em razão de elementos como sobrancelhas, nariz e lábios;

- Intensidade de Iluminação Conhecida e Constante: A intensidade da iluminação deve ser conhecida a priori para que o ajuste do histograma seja previamente realizado. Além disso, ela deve permanecer constante sobre a face;

- Posição da Face Conhecida: A determinação da região da imagem que contem a face é realizada manualmente à priori, sendo assim é importante que a posição da face no vídeo seja conhecida;

- Pose Controlada: O modelo proposto processa dados para situações de faces frontais, assim sendo é necessário que os ângulos de rolagem, arfagem e cambagem da cabeça sejam mínimos;

- Distância da Câmera Constante: O sistema é calibrado para lidar com faces posicionadas a uma distância constante da câmera. Mo- 
vimentos de aproximação e afastamento devem, portanto, ser evitados ao máximo;

- Ausência de Oclusões: Não há nenhum pré-processamento de deteç̧ão e compensação de oclusões, desta forma, os seguimentos de vídeo a serem analisados não devem conter quadros com oclusão total ou parcial da face;

- Ausência de Deficiências Musculares e Deformações na Face: $O$ sistema não possui meios de detectar anomalias, deformações ou deficiências musculares, tanto as naturais como as ocasionadas por tratamentos estéticos, como a aplicação de toxina botulínica. Assim as faces a serem analisadas não devem apresentar tais condições.

É necessário apontar que nenhuma restrição é imposta quanto a deformações transientes na face induzidas por fenômenos alheios às expressões faciais relacionadas às emoções, categoria na qual se encaixam, sobretudo, aquelas introduzidas pelo ato da fala.

Esta característica diferencia este trabalho de outros apresentados na literatura, visto que estes não consideram a influência desta atividade na classificação de expressões, ignorando-a, ou recomendam explicitamente que os vídeos analisados não contenham este tipo de efeitos. Conforme proposto no modelo, a identificação de expressões faciais fornece pistas sobre o estado emocional do interlocutor, as quais são as únicas informações utilizadas posteriormente no estimador.

O segundo grupo, requisitos semânticos, lida com a emoção transmitida no vídeo e o quão clara esta transmissão é se analisada única e exclusivamente pela ótica das expressões faciais. Enquanto a utilização de expressões faciais para indicar emoções é, em geral, um fenômeno involuntário, universal e espontâneo em situações reais, elas nem sempre estão presentes em situações de atuação.

Uma vez que os bancos de dados de testes multimodais disponíveis para treinamento de sistemas afetivos são fruto de vídeos utilizando voluntários ou atores amadores, a observação de expressões caricatas ou equivocadas é 
bastante comum. Naturalmente, a utilização de cenas semanticamente imprecisas culmina em análises computacionais imprecisas, em especial por vícios durante as etapas de treinamento.

À luz desta percepção, é necessário selecionar um conjunto de vídeos que atenda os requisitos técnicos e desenvolver um experimento preliminar a fim de validar a mensagem transmitida. Ambas etapas são detalhadas a seguir.

\subsubsection{Banco de Dados}

Para a realização do experimento era necessário utilizar um corpus que respeitasse as limitações técnicas delineadas e havia clara preferência por vídeos multimodais, que envolvessem o ato da fala, o qual se antecipava como desafio. Tendo estes fatores em vista, o "eNTERFACE'05 Audio-Visual Emotion Database [Martin et al, 2006], foi selecionado.

Uma vez que os atores presentes nos vídeos do corpus são amadores, observou-se que, por vezes, as expressões faciais não eram condizentes com a emoção que se desejava exprimir. Posto isso, todos os vídeos do banco de dados foram avaliados manualmente, resultando em um conjunto de cinquenta cenas consideradas, inicialmente, como exemplos de boa atuação. Ainda assim, tal escolha refletia especificamente o entendimento do autor sobre a qualidade da mensagem transmitida. Um experimento de classificação manual foi realizado com a ajuda de voluntários, no intuito validar tal entendimento.

\subsubsection{Análise Semântica e Seleção}

O experimento idealizado para a realização da análise dos vídeos sob uma ótica semântica consiste em exibir as cenas selecionadas sequencialmente a um conjunto de voluntários. Cada cena é exibida, sem som, duas vezes e, após assistir o vídeo, cada voluntário deve relacioná-la a uma das seguintes emoções: felicidade, tristeza, raiva ou medo. A classificação é obrigatória e cada clipe pode ser classificado em uma única categoria.

As tabelas a seguir detalham os resultados obtidos com esse experimento de classificação manual. 
Tabela 1: Classificação Manual no Experimento de Análise Semântica dos Vídeos de Felicidade

\begin{tabular}{lllll}
\hline Arquivo & Felicidade & Tristeza & Raiva & Medo \\
\hline s2_ha_2 & $100.0 \%$ & $0.0 \%$ & $0.0 \%$ & $0.0 \%$ \\
s4_ha_2 & $100.0 \%$ & $0.0 \%$ & $0.0 \%$ & $0.0 \%$ \\
s4_ha_4 & $100.0 \%$ & $0.0 \%$ & $0.0 \%$ & $0.0 \%$ \\
s12_ha_3 & $100.0 \%$ & $0.0 \%$ & $0.0 \%$ & $0.0 \%$ \\
s25_ha_2 & $94.1 \%$ & $0.0 \%$ & $5.9 \%$ & $0.0 \%$ \\
s29_ha_3 & $94.1 \%$ & $5.9 \%$ & $0.0 \%$ & $0.0 \%$ \\
\hline
\end{tabular}

É possível observar que há um alto índice de concordância na análise de vídeos de felicidade. À luz dos experimentos relatados na literatura, tal resultado é esperado, [Russel, 1994]. Acredita-se que uma explicação parcial para este fenômeno seja o reconhecimento comum das expressões de sorriso como marcadores da categoria felicidade.

Tabela 2: Classificação Manual no Experimento de Análise Semântica dos Vídeos de Tristeza

\begin{tabular}{lllll}
\hline Arquivo & Felicidade & Tristeza & Raiva & Medo \\
\hline s1_sa_1 & $0.0 \%$ & $25.0 \%$ & $18.8 \%$ & $56.3 \%$ \\
s2_sa_4 & $0.0 \%$ & $82.4 \%$ & $11.8 \%$ & $5.9 \%$ \\
s4_sa_1 & $0.0 \%$ & $94.1 \%$ & $0.0 \%$ & $5.9 \%$ \\
s14_sa_3 & $5.9 \%$ & $70.6 \%$ & $11.8 \%$ & $11.8 \%$ \\
s14_sa_5 & $70.6 \%$ & $5.9 \%$ & $11.8 \%$ & $11.8 \%$ \\
s29_sa_1 & $0.0 \%$ & $82.4 \%$ & $11.8 \%$ & $5.9 \%$ \\
s29_sa_3 & $0.0 \%$ & $64.7 \%$ & $5.9 \%$ & $29.4 \%$ \\
s33_sa_2 & $0.0 \%$ & $82.4 \%$ & $5.9 \%$ & $11.8 \%$ \\
s36_sa_2 & $0.0 \%$ & $88.2 \%$ & $0.0 \%$ & $11.8 \%$ \\
s42_sa_1 & $0.0 \%$ & $88.2 \%$ & $11.8 \%$ & $0.0 \%$ \\
s43_sa_1 & $0.0 \%$ & $100.0 \%$ & $0.0 \%$ & $0.0 \%$ \\
s43_sa_3 & $0.0 \%$ & $94.1 \%$ & $0.0 \%$ & $5.9 \%$ \\
s43_sa_4 & $0.0 \%$ & $100.0 \%$ & $0.0 \%$ & $0.0 \%$ \\
s43_sa_5 & $0.0 \%$ & $94.1 \%$ & $0.0 \%$ & $5.9 \%$ \\
\hline
\end{tabular}


Nestas cenas é evidente um aumento significativo na discordância entre a emoção nominal dos vídeos, tristeza, e a classificação realizada pelos voluntários quando comparado com os resultados obtidos para a categoria felicidade. Vídeos como o s14_sa_5 devem ser, notavelmente, desconsiderados no treinamento e análise computacional, uma vez que os voluntários o classificaram em uma categoria diferente da nominal.

Tabela 3: Classificação Manual no Experimento de Análise Semântica dos Vídeos de Raiva

\begin{tabular}{lllll}
\hline Arquivo & Felicidade & Tristeza & Raiva & Medo \\
\hline s2_an_2 & $31.3 \%$ & $6.3 \%$ & $43.8 \%$ & $18.8 \%$ \\
s4_an_2 & $0.0 \%$ & $23.5 \%$ & $76.5 \%$ & $0.0 \%$ \\
s4_an_5 & $0.0 \%$ & $0.0 \%$ & $76.5 \%$ & $23.5 \%$ \\
s14_an_1 & $0.0 \%$ & $0.0 \%$ & $88.2 \%$ & $11.8 \%$ \\
s25_an_2 & $5.9 \%$ & $17.6 \%$ & $52.9 \%$ & $23.5 \%$ \\
s28_an_4 & $0.0 \%$ & $70.6 \%$ & $29.4 \%$ & $0.0 \%$ \\
s29_an_2 & $94.1 \%$ & $0.0 \%$ & $5.9 \%$ & $0.0 \%$ \\
s29_an_4 & $70.6 \%$ & $17.6 \%$ & $5.9 \%$ & $5.9 \%$ \\
s33_an_2 & $6.3 \%$ & $25.0 \%$ & $56.3 \%$ & $12.5 \%$ \\
s36_an_3 & $11.8 \%$ & $35.3 \%$ & $35.3 \%$ & $17.6 \%$ \\
s37_an_1 & $11.8 \%$ & $47.1 \%$ & $35.3 \%$ & $5.9 \%$ \\
s38_an_1 & $0.0 \%$ & $0.0 \%$ & $88.2 \%$ & $11.8 \%$ \\
s43_an_2 & $0.0 \%$ & $0.0 \%$ & $100.0 \%$ & $0.0 \%$ \\
s43_an_3 & $0.0 \%$ & $0.0 \%$ & $94.1 \%$ & $5.9 \%$ \\
s43_an_4 & $0.0 \%$ & $0.0 \%$ & $100.0 \%$ & $0.0 \%$ \\
s43_an_5 & $0.0 \%$ & $0.0 \%$ & $100.0 \%$ & $0.0 \%$ \\
s44_an_4 & $0.0 \%$ & $0.0 \%$ & $70.6 \%$ & $29.4 \%$ \\
\hline
\end{tabular}

A classificação das cenas de raiva também se demonstrou menos uniforme do que àquela relativa aos vídeos de felicidade, aproximando-se dos resultados obtidos com os vídeos de tristeza. 
Tabela 4: Classificação Manual no Experimento de Análise Semântica dos Vídeos de Medo

\begin{tabular}{lllll}
\hline Arquivo & Felicidade & Tristeza & Raiva & Medo \\
\hline s2_fe_4 & $6.3 \%$ & $37.5 \%$ & $25.0 \%$ & $31.3 \%$ \\
s14_fe_2 & $0.0 \%$ & $35.3 \%$ & $52.9 \%$ & $11.8 \%$ \\
s24_fe_3 & $11.8 \%$ & $5.9 \%$ & $0.0 \%$ & $82.4 \%$ \\
s24_fe_4 & $0.0 \%$ & $23.5 \%$ & $0.0 \%$ & $76.5 \%$ \\
s25_fe_2 & $5.9 \%$ & $0.0 \%$ & $11.8 \%$ & $82.4 \%$ \\
s28_fe_2 & $5.9 \%$ & $5.9 \%$ & $82.4 \%$ & $5.9 \%$ \\
s33_fe_5 & $0.0 \%$ & $5.9 \%$ & $47.1 \%$ & $47.1 \%$ \\
s36_fe_2 & $0.0 \%$ & $23.5 \%$ & $5.9 \%$ & $70.6 \%$ \\
s37_fe_3 & $5.9 \%$ & $11.8 \%$ & $47.1 \%$ & $35.3 \%$ \\
s38_fe_3 & $0.0 \%$ & $17.6 \%$ & $5.9 \%$ & $76.5 \%$ \\
s42_fe_1 & $0.0 \%$ & $0.0 \%$ & $47.1 \%$ & $52.9 \%$ \\
s43_fe_2 & $0.0 \%$ & $0.0 \%$ & $0.0 \%$ & $100.0 \%$ \\
\hline
\end{tabular}

Os dados dispostos nas Tabelas 1 a 4, podem ser visualizados no gráfico apresentado na Figura 17. Assim para 100\% dos vídeos de "Felicidade" obtiveram $90 \%$ ou menos de classificações corretas, mas somente cerca de $70 \%$ resultaram em classificações unânimes. 


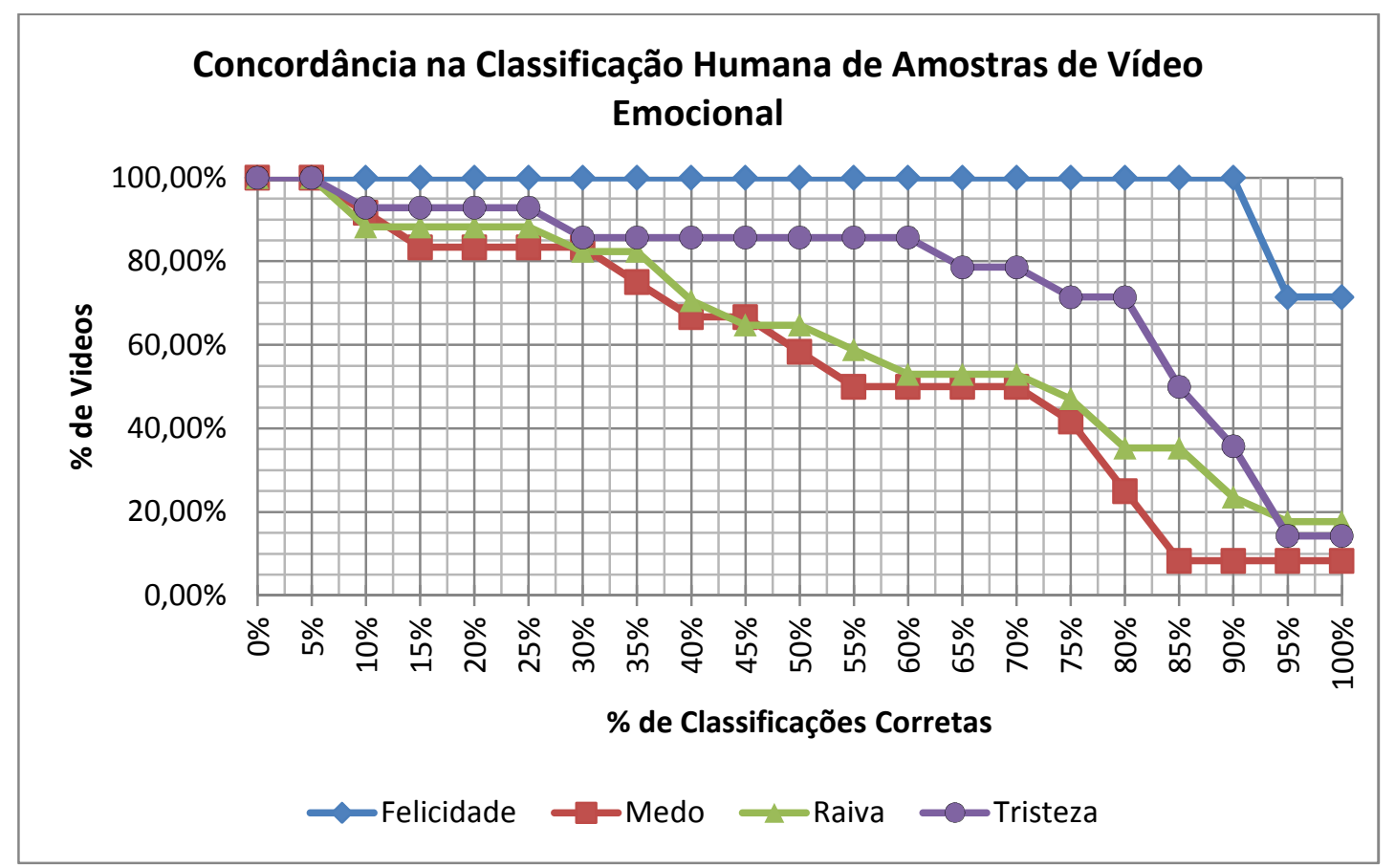

Figura 17: Concordância na Classificação Humana de Amostras de Vídeo Emocional

Postula-se que o senso comum sobre o reconhecimento de marcadores de tristeza, raiva e medo não se demonstre tão uniforme quanto à relação entre sorriso e felicidade. Desta forma, não somente as pessoas demonstram maior dificuldade em relacionar tais emoções, mas principalmente os voluntários filmados na elaboração do banco de dados também se deparam com barreiras ao tentar representar tais emoções.

Tabela 5: Matriz de Confusão do Experimento de Classificação Manual

\begin{tabular}{lllll}
\hline & Felicidade & Tristeza & Raiva & Medo \\
\hline Felicidade & $\mathbf{9 8 , 3 2 \%}$ & $0,84 \%$ & $0,84 \%$ & $0,00 \%$ \\
Tristeza & $5,49 \%$ & $\mathbf{7 6 , 7 9 \%}$ & $6,33 \%$ & $11,39 \%$ \\
Raiva & $13,59 \%$ & $14,29 \%$ & $\mathbf{6 2 , 3 7 \%}$ & $9,76 \%$ \\
Medo & $2,96 \%$ & $13,79 \%$ & $\mathbf{2 7 , 0 9 \%}$ & $\mathbf{5 6 , 1 6 \%}$ \\
\hline
\end{tabular}

A matriz de confusão apresentada na Tabela 5 demonstra que, como esperado, a classificação humana possui alto índice de acerto, atingindo de- 
sempenho sempre superior àquele de um classificador aleatório [Russel, 1994]. É importante ressaltar que tal matriz inclui também casos como s28_fe_2, s29_an_2 e s14_sa_5, onde é admitido que a classificação discordante possa ser explicada por deficiência semântica, isto é, falha do ator ao tentar transmitir a emoção especificada.

Tabela 6: Concordância para Cenários de Classificação Forçada [Russel, 1994]

\begin{tabular}{lcccccc}
\hline & \multicolumn{6}{c}{ Expressão Facial } \\
\cline { 2 - 7 } Grupo Cultural & Felicidade Surpresa & Tristeza & Medo & Desgosto Raiva \\
\hline Ocidentais & $96,4 \%$ & $87,5 \%$ & $80,5 \%$ & $77,5 \%$ & $82,6 \%$ & $81,2 \%$ \\
Não Ocidentais, letrados & $89,2 \%$ & $79,2 \%$ & $76,0 \%$ & $65,0 \%$ & $65,0 \%$ & $63,0 \%$ \\
Populações isoladas, não & $92,0 \%$ & $36,0 \%$ & $52,0 \%$ & $46,0 \%$ & $29,0 \%$ & $56,0 \%$ \\
letradas & & & & & & \\
\hline
\end{tabular}

É proposto que para um vídeo ser considerado semanticamente correto ele deve atingir um nível de concordância de ao menos $90 \%$ da concordância esperada para uma análise realizada por um grupo considerado de cultura ocidental. Desta forma, as concordâncias mínimas admissíveis para cada categoria são $86.8 \%, 69.8 \%, 73.1 \%$ e $72.5 \%$, resultando em sete vídeos para felicidade, seis para medo, oito para raiva e dez para tristeza, respectivamente.

\subsection{Detecção de Expressões Faciais}

A detecção das expressões faciais foi realizada utilizando-se o aplicativo eMotion nos 31 vídeos originalmente selecionados. O procedimento de análise envolve $o$ ajuste manual de uma malha tridimensional sobre a região da face no vídeo, o que se dá mediante a indicação do posicionamento dos olhos, boca e contorno da face. 


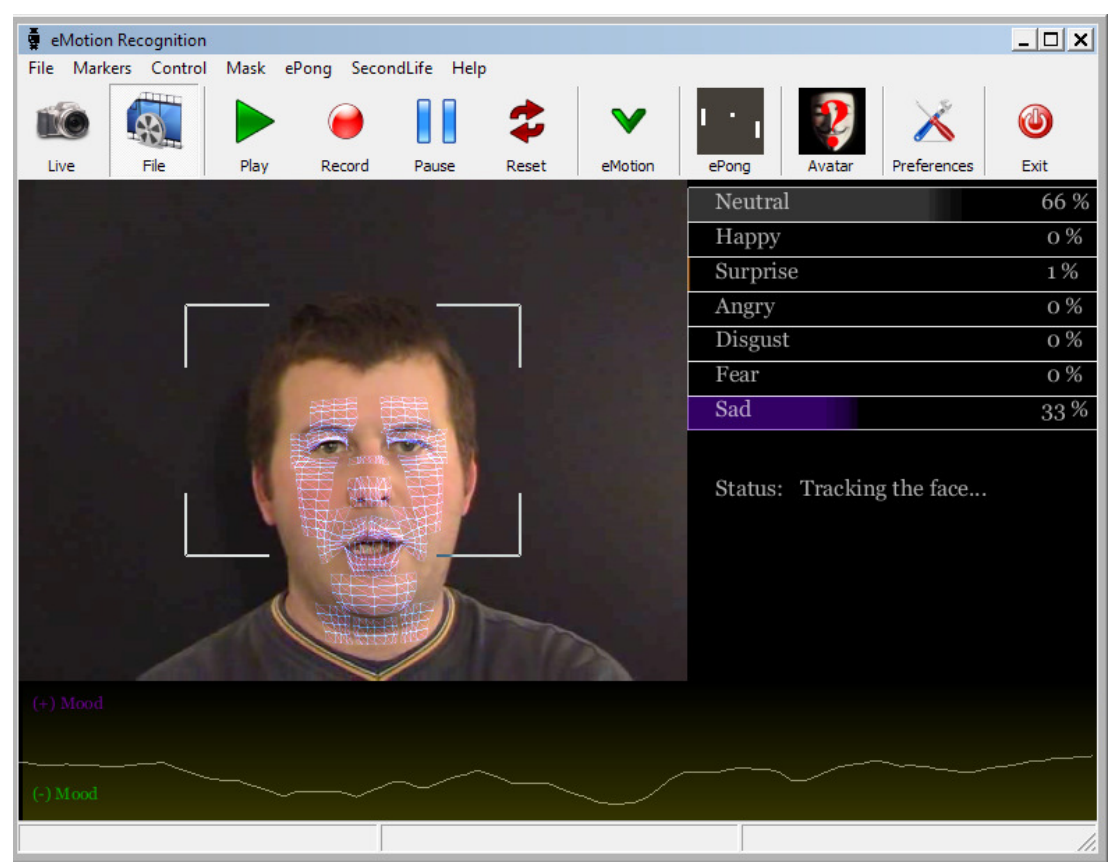

Figura 18: Interface do aplicativo eMotion durante a análise de um vídeo.

A Figura 18 mostra a interface do aplicativo eMotion durante a análise de um dos vídeos selecionados. À esquerda é possível visualizar o vídeo, quadro a quadro, e como o posicionamento e deformação da malha acompanha a musculatura facial. À direita é possível ler as estimativas que o programa faz para cada uma das expressões para a qual realiza a detecção de padrões. $O$ gráfico, na parte inferior da Figura 18, é a valência do estado emocional do interlocutor por meio da integração quadro a quadro das estimativas.

Após o ajuste da malha ser realizado, é possível analisar o vídeo e os resultados são exibidos em tempo real pelas barras na parte direita da tela, cada uma identificando propriamente a emoção. Além da exibição na tela, o aplicativo também cria um arquivo de texto contendo o número do quadro e os resultados parciais.

Atenção especial deve ser dada ao comportamento da malha durante a execução do vídeo. O aplicativo a ajusta quadro a quadro com base na localização automática das características manualmente selecionadas durante a primeira etapa. Situações nas quais a localização automática falha e a malha "descola" da face ocorrem em diversos vídeos e são especialmente comuns quando há deformações induzidas pelos movimentos associados à fala. Vídeos 
para os quais esse fenômeno foi observado foram descartados. Ao final, 31 vídeos foram analisados propriamente.

\subsection{Calibração dos Filtros}

Cada emoção modelada neste experimento - isto é, felicidade, tristeza, raiva e medo - será submetida separadamente a um processo de filtragem utilizando a técnica de filtro de Kalman proposta. Os filtros devem ser individualmente calibrados com relação à variância esperada dos ruídos de observação e de processo. Também é necessário determinar a constante de ganho e a constante de tempo de cada um dos sistemas de primeira ordem utilizados nos filtros.

Assim, para cada uma das emoções de interesse é necessário calibrar os seguintes parâmetros:

$K$, constante de ganho do sistema;

$\tau$, constante de tempo do sistema;

$w$ é a covariância do ruído do processo;

$v$ é a covariância do ruído na observação.

Os parâmetros $K, \tau$ e $w$ foram adotados como constantes para todas as quatro emoções de interesse a fim de simplificar o procedimento de ajuste; tal hipótese baseia-se no fato que a mecânica facial é a mesma, independente da expressão.

As trinta e uma sequências consideradas válidas foram então separadas em dois grupos: dezesseis vídeos para serem utilizados no algoritmo de simulação-otimização de ajuste dos filtros e quinze vídeos para realização de testes de classificação.

O sistema foi então calibrado automaticamente por meio da heurística descrita no Algoritmo 1 com as seguintes condições iniciais:

$$
\begin{aligned}
& T_{0}=2,500.00 ; \\
& T_{a m b}=10 ;
\end{aligned}
$$




$$
K_{t}=0.9995
$$

A partir destas condições são realizadas 11.041 iterações até que o sistema estabilize. Uma vez que esta heurística não garante convergência para um ponto de mínimo absoluto, o procedimento padrão envolve diversas repetições a partir de vetores $Q$ e $R$ iniciais diversos. Para este experimento foram realizadas dezoito rodadas, cada uma delas partindo de $w$ e $v$ escolhidos aleatoriamente de uma distribuição uniforme sobre o intervalo [1e-3, 1e3]. Para as condições do experimento, cada rodada exigiu cerca de duas horas de processamento de um computador doméstico.

Este procedimento resultou nos valores de energia global para o sistema listados na Tabela 7.

Tabela 7: Resultados da heurística de ajuste dos filtros

\begin{tabular}{cccc}
\hline Execução & $E_{g}$ & Execução & $E_{g}$ \\
\hline 1 & 447 & 10 & 540 \\
2 & 452 & 11 & 546 \\
3 & 459 & 12 & 4575 \\
4 & 471 & 13 & 4.575 \\
5 & 478 & 14 & 4.618 \\
6 & 481 & 15 & 5.862 \\
7 & 481 & 16 & 5.998 \\
8 & 485 & 17 & 6.124 \\
9 & 498 & 18 & 6.147 \\
\hline
\end{tabular}

Uma vez que a energia global é diretamente proporcional ao número de pontos erroneamente classificados nas trajetórias emocionais, os melhores parâmetros obtidos correspondem àqueles selecionados para 0 caso $E_{g \text {, mínimo }}=447$. É interessante perceber que o sistema de ajuste automático convergiu diversas vezes para um mínimo na região de $E_{g \text {, minimo }}=500$, mesmo partindo de parâmetros iniciais aleatórios selecionados em um espectro amplo. 
O perfil de convergência desta solução pode ser analisado na Figura 19. Por meio desta visualização é possível compreender melhor o mecanismo de convergência da heurística, o qual faz uso da condição de temperatura do sistema para possibilitar maior variação na aceitação de soluções. De fato, estados intrinsicamente mais instáveis, ou seja, com maior energia global, podem vir a ser aceitos a fim de possibilitar que o sistema "escape" de mínimos locais. À medida que o sistema resfria, soluções potencialmente ruins tem menor chance de aceitação. Finalmente o sistema se estabiliza perto de um ponto mínimo.

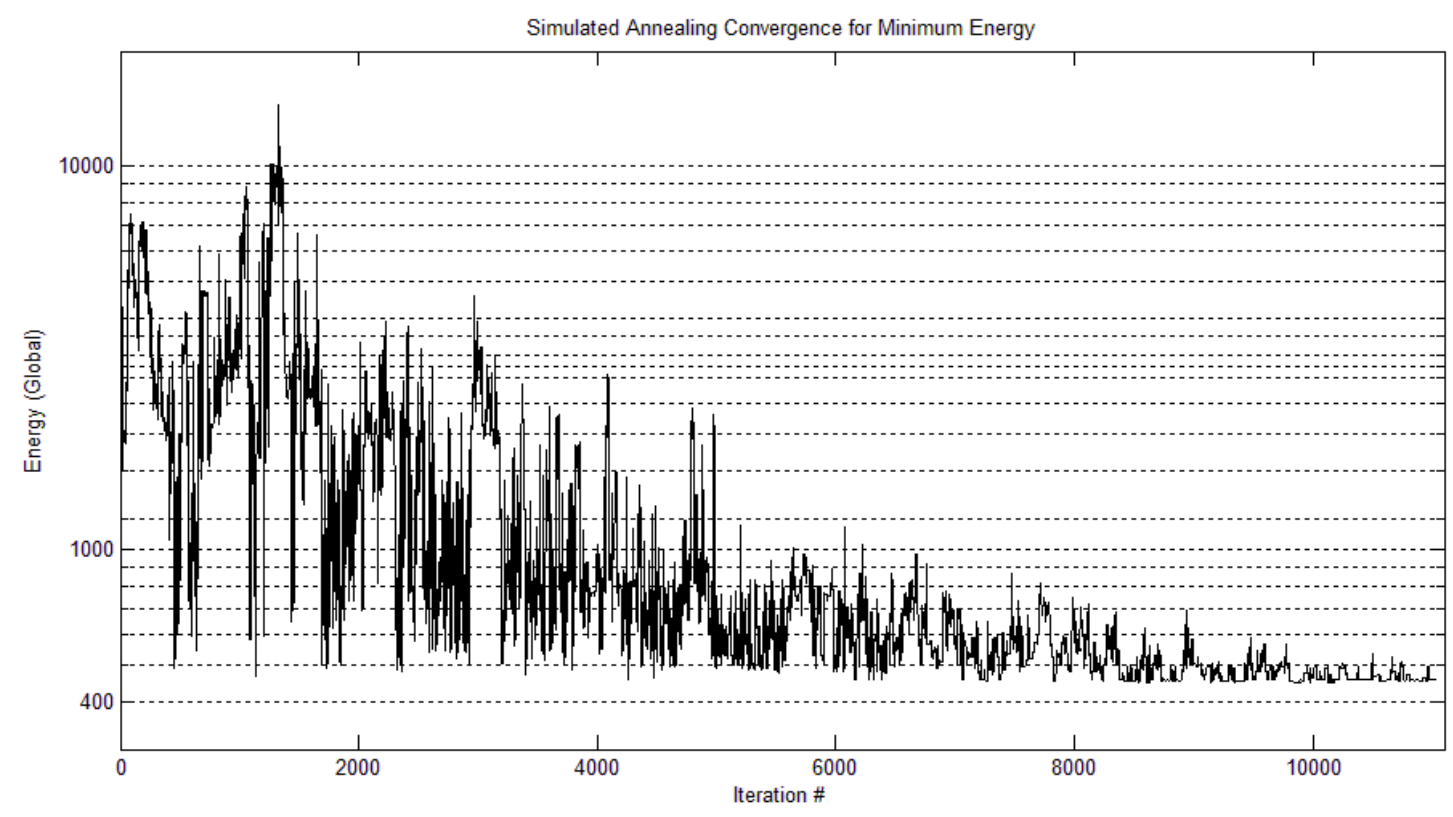

Figura 19: Convergência para a melhor solução obtida utilizando a heurística de simulação-otimização proposta.

Desta maneira, foram obtidos os seguintes parâmetros para calibração dos filtros neste experimento.

Tabela 8: Parâmetros dos Filtros de Kalman para Dados do eMotion

\begin{tabular}{lcccc}
\hline & $\boldsymbol{w}$ & $\boldsymbol{v}$ & $\mathbf{K}$ & $\boldsymbol{\tau}$ \\
\hline Felicidade & 207.91 & 692.04 & 5 & 1,5 \\
Raiva & 79.16 & 558.61 & 5 & 1,5
\end{tabular}




\begin{tabular}{lllll} 
Tristeza & 270.90 & 631.64 & 5 & 1,5 \\
Medo & 490.95 & 483.38 & 5 & 1,5 \\
\hline
\end{tabular}

Um filtro de média móvel também foi utilizado nos dados provindos do eMotion, considerando a amostragem média sobre vinte quadros. A Figura 20 traz os dados exibidos na Figura 15 para as duas modalidades de filtragem:
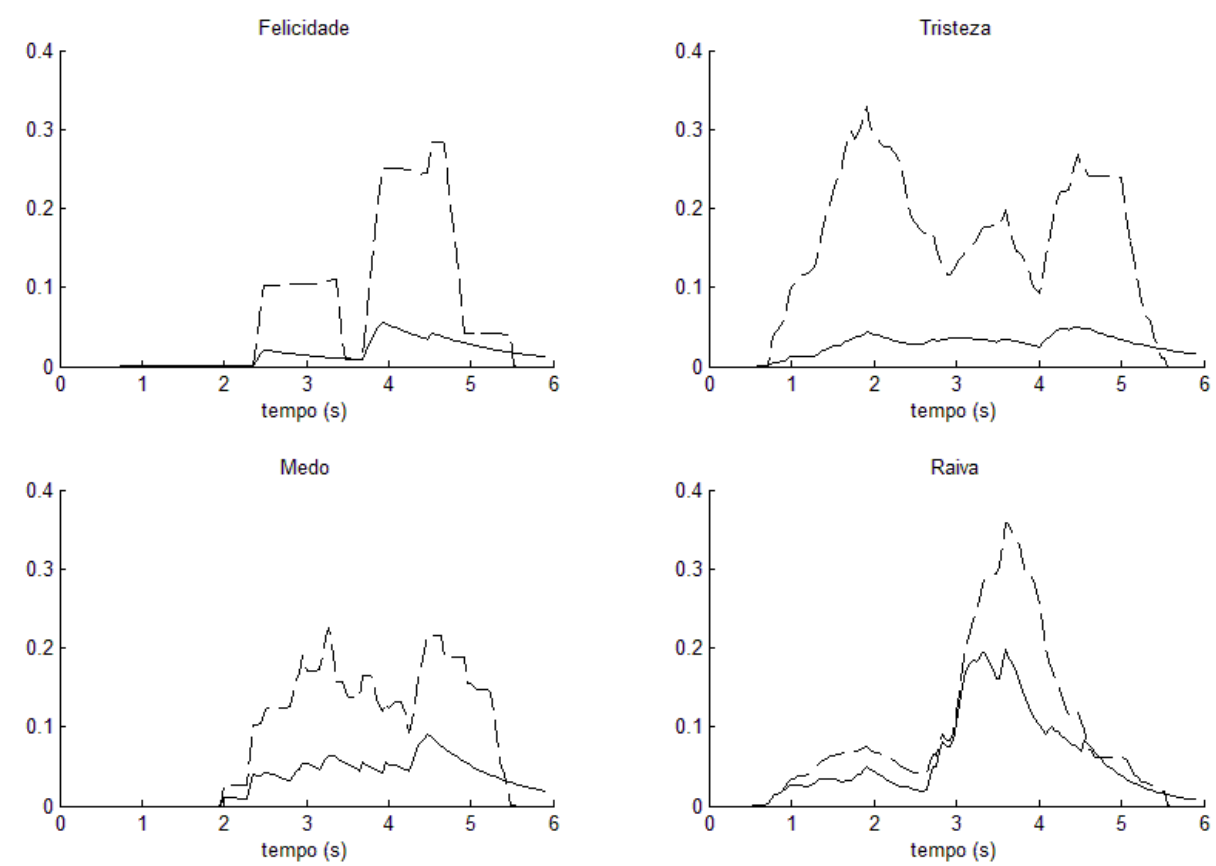

Figura 20: Dados do filtro ilustrativo após filtragem. A linha contínua representa o filtro de Kalman e a linha tracejada o filtro de média móvel.

A resposta dos filtros de média móvel nos gráficos da Figura 20 permite visualizar que, mesmo tratando-se de um vídeo com conteúdo emocional de raiva, o algoritmo de detecção de expressões faciais apresenta uma inclinação a caracterizá-lo como "tristeza", uma vez que a área sob a curva é claramente maior para esta categoria.

Durante a análise dos vídeos selecionados, foi possível perceber que tanto "tristeza" quanto "felicidade" são categorias para as quais o detector de expressões faciais apresenta maior sensibilidade. Tal sensibilidade acarreta dificuldades na classificação de vídeos de "medo" e "raiva". 
A utilização do filtro de Kalman, por sua vez, permite o ajuste individual do ruído de observação e do ruído de processo. Desta forma, sinais para os quais o detector é particularmente sensível e, portanto, apresenta diversos falsos positivos podem ser modelados como processos com um ruído de observação mais significativo.

A heurística de ajuste automático dos parâmetros demonstra convergência para uma situação condizente com esta interpretação, o que pode ser observado pela distribuição de valores no vetor $\boldsymbol{v}$, no qual "tristeza" e "felicidade" apresentam os maiores valores.

Um raciocínio similar permite interpretar o vetor de ruídos de processo, $\boldsymbol{w}$. Uma vez que o detector de expressões faciais foi desenvolvido e calibrado para a análise de imagens estáticas, não há nenhum tratamento quanto às deformações faciais induzidas na face durante a fala. Tais deformações, quando examinadas quadro a quadro podem vir a ser classificadas como alguma das categorias de interesse. $O$ estudo dos vídeos e das representações típicas das expressões relacionadas a cada categoria permite observar que, por exemplo, a vocalização de algumas palavras posiciona a boca instantaneamente em uma posição similar a um sorriso ou que a fala induz frequentemente uma distorção assimétrica na face, a qual é característica da categoria "medo". Assim, o vetor de ruído de observação apresenta valores condizentes com estas observações, incluindo um valor de destaque para a emoção "medo".

\subsection{Superfície de Dinâmica Emocional}

Após a obtenção do sinal filtrado utilizando o filtro de Kalman, é necessário realizar a fusão dos quatro sinais por meio da superfície de dinâmica emocional, SDE. Para tanto é necessário especificar a superfície e posicionar os atratores.

Para esse experimento, a SDE foi definida como um paraboloide na forma:

$$
\gamma(x, y)=\left(x, y, a x^{2}+b y^{2}\right),
$$




$$
a=b=0,6 \text {. }
$$

Os atratores foram posicionados da seguinte maneira:

Tabela 9: Posicionamento dos Atratores.

\begin{tabular}{cc}
\hline Emoção & Posição do Atrator \\
\hline Felicidade & {$[60,60,0]$} \\
Raiva & {$[-60,60,0]$} \\
Tristeza & {$[-60,-60,0]$} \\
Medo & {$[60,-60,0]$} \\
\hline
\end{tabular}

Considerando este posicionamento, é possível analisar o estado emocional a partir do quadrante no qual a partícula se encontra, conforme diagramado na Figura 21:

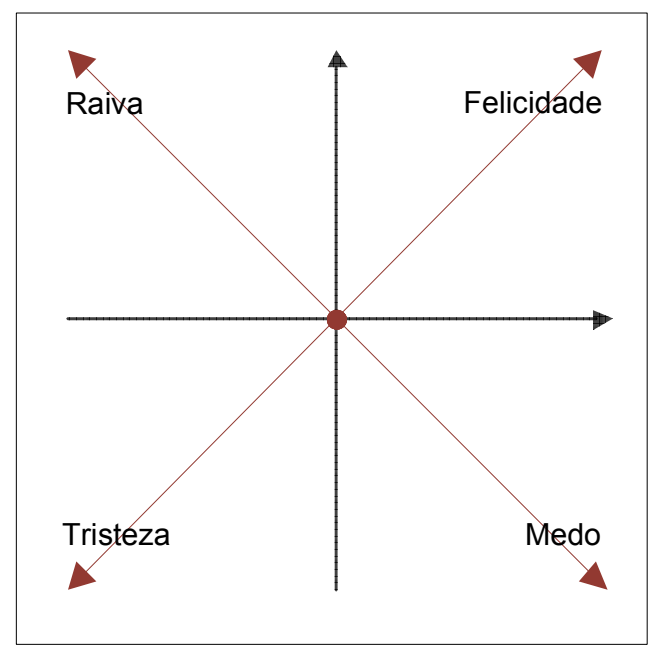

Figura 21: Descrição do Estado Emocional com Base em Quadrantes 


\subsection{Resultados}

Quatorze vídeos foram analisados utilizando o modelo proposto e o aplicativo eMotion como módulo detector de expressões faciais associadas a emoções. A Tabela 10 apresenta as classificações obtidas.

Tabela 10: Resultados do Experimento

\begin{tabular}{cccc}
\hline \multirow{2}{*}{$\#$} & Arquivo & \multicolumn{2}{c}{ Classificação } \\
\cline { 3 - 4 } & & Humana & Sistema \\
\hline 1 & S1sa1 & Tristeza & Tristeza \\
2 & S38an1 & Raiva & Raiva \\
3 & S38fe3 & Medo & Medo \\
4 & S42sa1 & Tristeza & Tristeza \\
5 & S43ha1 & Felicidade & Felicidade \\
6 & S43an2 & Raiva & Raiva \\
7 & S43an3 & Raiva & Raiva \\
8 & S43an4 & Raiva & Raiva \\
9 & S43fe2 & Medo & Medo \\
10 & S42fe1 & Medo & Medo \\
11 & S43sa1 & Tristeza & Tristeza \\
12 & S43sa3 & Tristeza & Tristeza \\
13 & S43sa4 & Tristeza & Tristeza \\
14 & S43sa5 & Tristeza & Raiva \\
\hline
\end{tabular}

As trajetórias obtidas para algumas partículas podem ser vistas nas Figuras 22 e 23. 

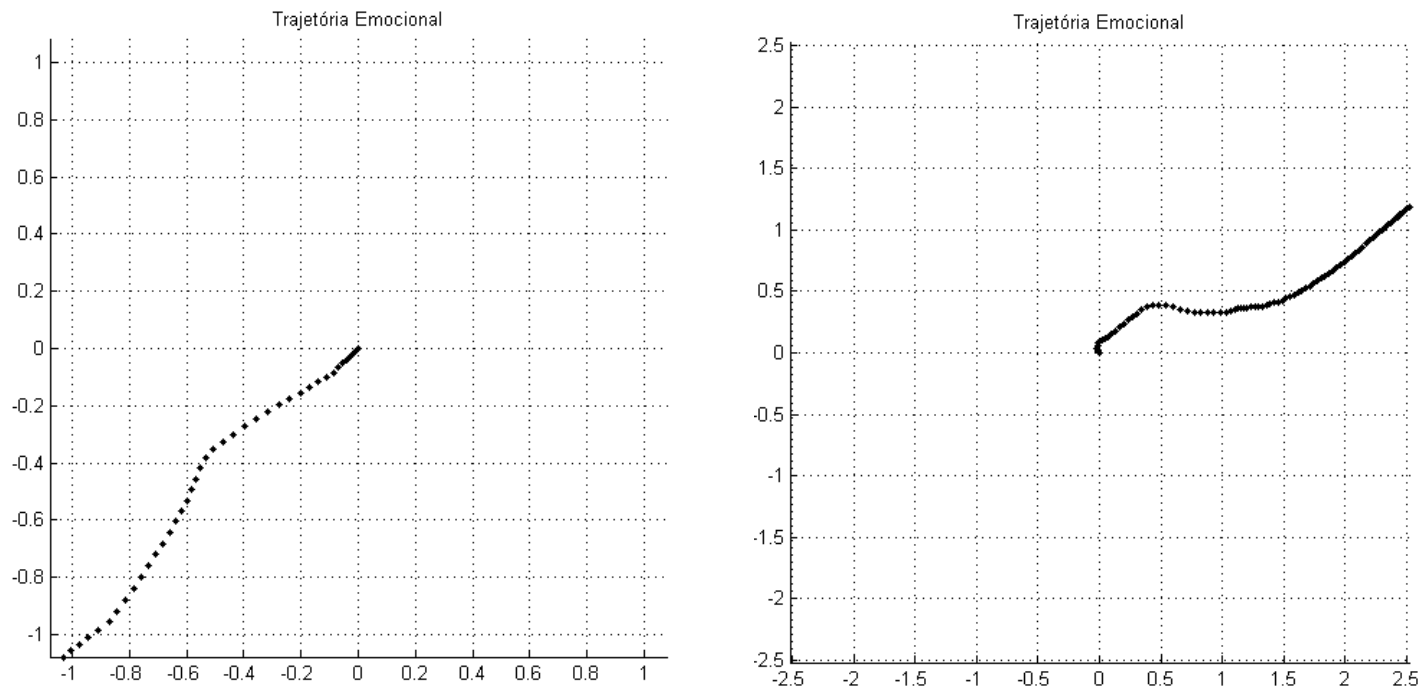

Figura 22: Trajetórias emocionais para os casos 1 (esquerda) e 5 (direita).
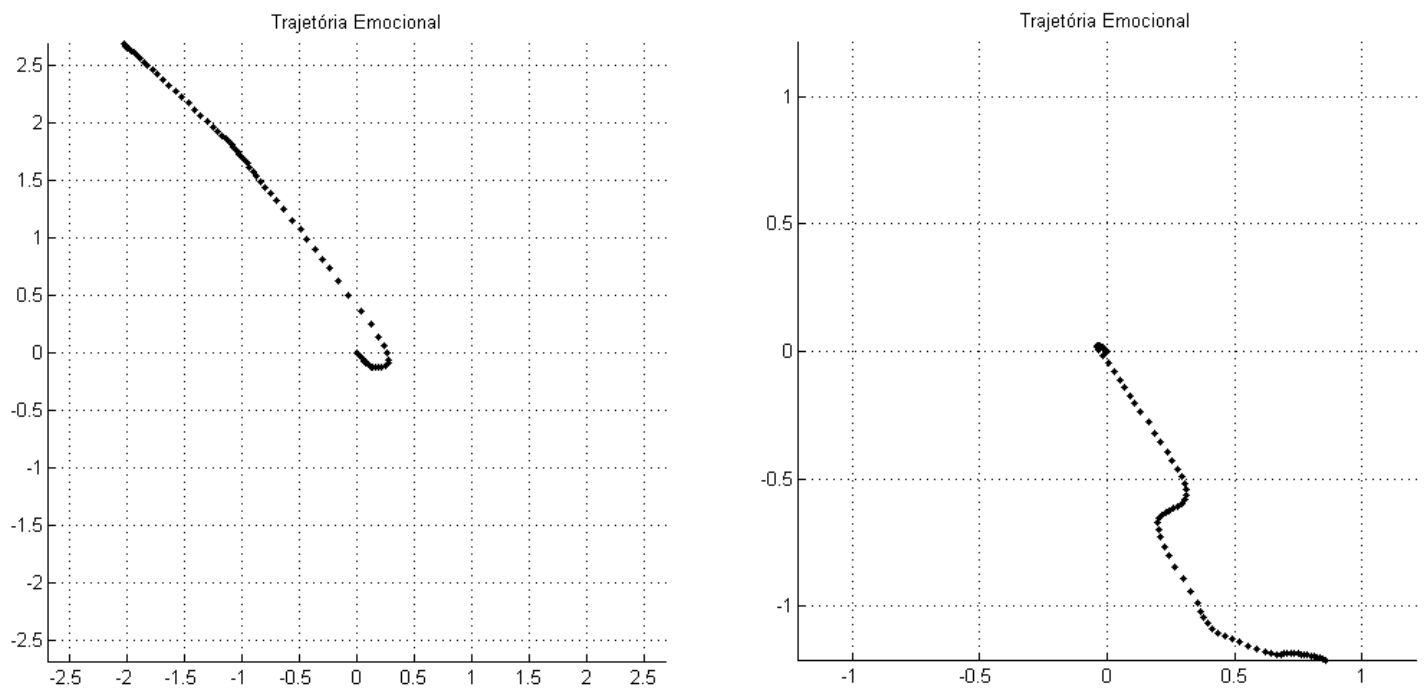

Figura 23: Trajetórias emocionais para os casos 7 (esquerda) e 10 (direita).

O caso número 14 deve ser destacado face à discordância entre a análise humana e a do sistema, mostrado na Figura 24. 


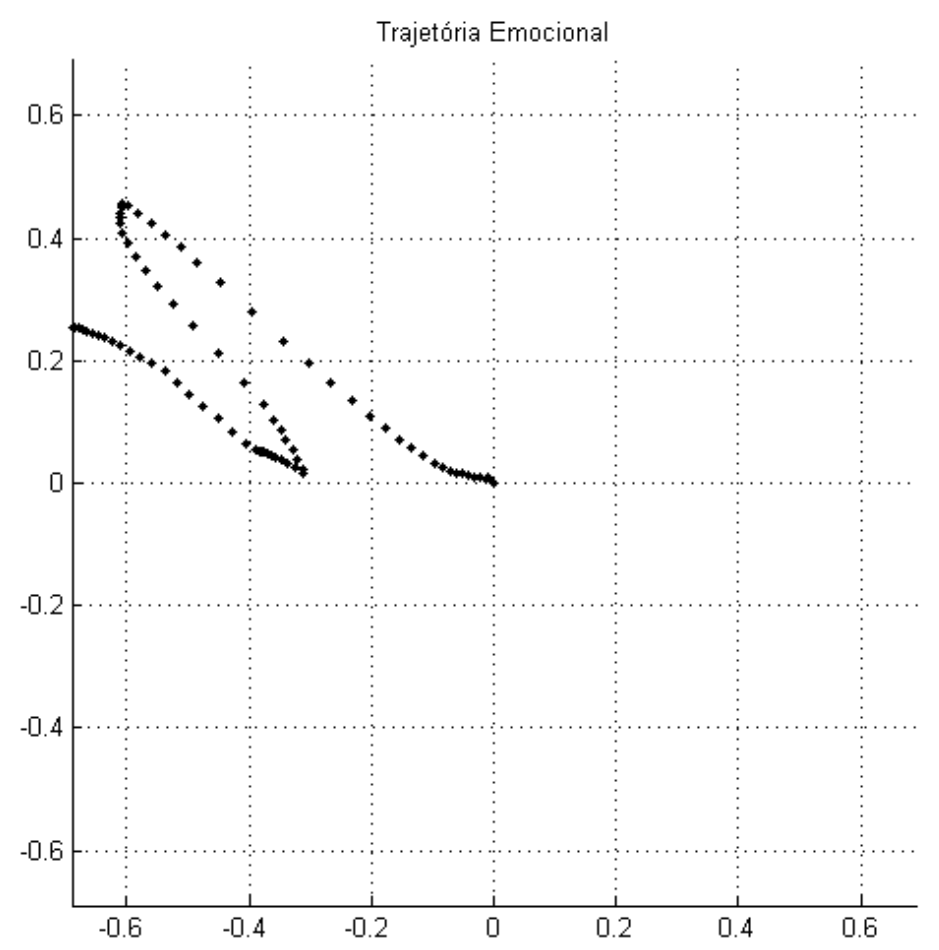

Figura 24: Trajetória emocional para o caso 14, falha.

Observou-se também que o tempo de processamento foi consistentemente cerca de duas ordens de grandeza menor que a duração dos vídeos. A arquitetura proposta pode, portanto, ser utilizada para a análise em tempo real.

\subsection{Discussão}

A comparação entre a análise do sinal como provindo do eMotion e o sinal filtrado, seja pelo filtro de média móvel ou o filtro de Kalman, fornece subsídios para afirmar que os processos de filtragem possibilitaram uma classificação mais precisa dos vídeos. O uso de uma trajetória sobre uma superfície permite acompanhar a evolução da emoção no tempo, determinando-se não somente sua característica mais dominante como também permitindo que variações possam ser identificadas.

O caso número 14 demonstra uma situação de falha, onde a partícula oscila sem uma definição clara de qual a emoção do interlocutor. Utilizando o critério de quadrantes apresentado, o sistema classifica o vídeo como "raiva".

O experimento também demonstrou que o detector de expressões faciais (no caso, o aplicativo eMotion) é um ponto crítico para a construção de 
sistemas robustos de determinação da emoção demonstrada pelo interlocutor. Em particular, acredita-se que sensores capazes de estimar mais adequadamente a face neutra do interlocutor e também de tratar as deformações na face induzidas pela fala, possibilitariam grandes ganhos no desempenho.

Além dos resultados do experimento em si, deve-se ressaltar que a utilização da heurística de ajuste dos parâmetros dos filtros de Kalman convergiu para uma configuração para a qual um entendimento físico é possível e corresponde à impressão inicial sobre os vídeos selecionados para análise. 


\section{Capítulo 5: Conclusão e Trabalhos Futuros}

Este trabalho apresentou um modelo matemático para inferência do estado emocional de um interlocutor por meio da análise de expressões faciais. O modelo apresentado diferencia-se dos sistemas apresentados na literatura por duas razões principais: a utilização de um modelo dinâmico contínuo para representação dos estados emocionais e a existência de uma heurística para ajuste automático dos parâmetros de tratamento de sinal.

O estudo de caso demonstrou a viabilidade do modelo proposto para o pós-processamento de sinais captados por algoritmos comerciais de identificação de expressões faciais. A classificação humana e a inferência obtida apresentam alto grau de concordância, havendo classificado 13 dos 14 vídeos de teste na mesma categoria. Tais resultados foram obtidos por meio de um sistema agnóstico ao interlocutor, isto é, o motor de inferência apresentado no estudo de caso não levava em conta as diferenças interpessoais no que tange diferentes comportamentos e expressões emocionais.

Uma alternativa para a inclusão de tais diferenças interpessoais no modelo seria a utilização de uma superfície de dinâmica emocional (SDE) variante no tempo, isto é, $\gamma(\mathrm{x}, \mathrm{y}, \mathrm{t})$, e a inclusão de um sistema de aprendizado capaz de inferir a forma da superfície por meio da observação das reações do interlocutor e alterá-la ao longo do tempo. Tal fenômeno demonstrar-se-ia análogo à rotina social pela qual as pessoas conhecem umas às outras.

O desenvolvimento de um sistema adaptativo, porém, é um trabalho intrinsecamente interdisciplinar, com grande ênfase em avaliações e modelos psicológicos. A SDE proposta nesse trabalho e os experimentos realizados contemplam, portanto, apenas regiões próximas à origem para as quais se espera um comportamento emocional razoável.

Assim, deve-se ressaltar que, embora este trabalho apresente fundamentação para sistemas complexos de inferência emocional, o estudo de caso apresentado utilizou-se intencionalmente de uma SDE simples, com a qual os resultados foram de sobremaneira satisfatórios.

Uma segunda vertente de continuidade à pesquisa está relacionada com a duração dos vídeos analisados. A iteração homem-máquina está repleta de situações nas quais a obtenção um entendimento geral sobre o estado 
emocional do usuário durante uma iteração de longo prazo é de interesse. 0 estudo da relação entre a topologia da SDE e o intervalo de análise pode ser abordado à luz da proposição de uma heurística de transformações tal que a partir de uma dada SDE, ajustada para um intervalo, seja possível determinar uma família de SDEs sobre as quais análises de diferentes horizontes temporais sejam realizáveis.

Em tempo, o desenvolvimento desta pesquisa propiciou a publicação de três artigos científicos, [Gonçalves et al, 2011A], publicado nos Anais do XXXI Congresso da Sociedade Brasileira de Computação e premiado como um dos três melhores artigos do congresso; [Gonçalves et al 2011B], apresentado na Mexican International Conference on Artificial Intelligence e selecionado para publicação no periódico Polibits; [Gonçalves et al, 2012] publicado no Journal of the Brazilian Computer Society (JBCS). 


\section{REFERÊNCIAS}

[Azcarate et al, 2005] AZCARATE, Aitor et al. Automatic facial emotion recognition. Universiteit van Amsterdam, 2005.

[Baltrusaitis, 2011] BALTRUSAITIS, Tadas et al. Real-time inference of mental states from facial expressions and upper body gestures. In: Automatic Face \& Gesture Recognition and Workshops (FG 2011), 2011 IEEE International Conference on. IEEE, 2011. p. 909-914.

[Bartlett et al, 1996] BARTLETT, M. Stewart et al. Classifying facial action. Advances in neural information processing systems, p. 823-829, 1996.

[Black et al, 1997] BLACK, Michael J.; YACOOB, Yaser. Recognizing facial expressions in image sequences using local parameterized models of image motion.International Journal of Computer Vision, v. 25, n. 1, p. 23-48, 1997

[Breazeal, 2003] BREAZEAL, Cynthia. Emotion and sociable humanoid robots. International Journal of Human-Computer Studies, v. 59, n. 1, p. 119-155, 2003.

[Brothers, 1999] Brothers, L. (1999). Emotion and the Human Brain. In F. Keil \& R. Wilson (Eds.), The MIT Encyclopedia of the Cognitive Sciences (1st ed., pp. 271-273). Cambridge: The MIT Press.

[Cohen et al, 2004] COHEN, Ira et al. Semisupervised learning of classifiers: Theory, algorithms, and their application to human-computer interaction. Pattern Analysis and Machine Intelligence, IEEE Transactions on, v. 26, n. 12, p. 1553-1566, 2004.

[Cohn et al, 1997] COHN, J. F. et al. Automated face coding: A computer-vision based method of facial expression analysis. Psychophysiology, 1997.

[Cohn et al, 1998] COHN, Jeffrey F. et al. Feature-point tracking by optical flow discriminates subtle differences in facial expression. In: Automatic Face and Gesture Recognition, 1998. Proceedings. Third IEEE International Conference on. IEEE, 1998. p. 396-401.

[Damásio, 1996] DAMÁSIO, A. R. O Erro de Descartes; trad. Dora Vicente e Georgina Segurado. São Paulo: Companhia das Letras, 1996.

[Darwin, 1872] DARWIN, Charles. The expression of the emotions in man and animals. 1872, Oxford University Press, USA, 2002. 
[Deigh, 1994] DEIGH, John. Cognitivism in the Theory of Emotions. Ethics, p. 824-854, 1994.

[Ekman et al, 1969] EKMAN, Paul et al. Pan-cultural elements in facial displays of emotion. Science, v. 164, n. 3875, p. 86-88, 1969.

[Ekman et al, 1972] EKMAN, Paul; FRIESEN, Wallace V.; ELLSWORTH, Phoebe. Emotion in the Human Face: Guide-lines for Research and an Integration of Findings: Guidelines for Research and an Integration of Findings. Pergamon, 1972.

[Ekman et al, 1976] EKMAN, Paul; FRIESEN, Wallace V. Measuring facial movement. Journal of Nonverbal Behavior, v. 1, n. 1, p. 56-75, 1976.

[Ekman et al, 1978] EKMAN, Paul; Friesen, W. V. Facial Action Coding System: A Technique for the Measurement of Facial Movement. (C. P. Press, Ed.). Palo Alto: Consulting Psychologists Press, 1978

[Ekman et al, 1986] EKMAN, Paul; FRIESEN, Wallace V. A new pan-cultural facial expression of emotion. Motivation and emotion, v. 10, n. 2, p. 159$168,1986$.

[Ekman, 1992] EKMAN, Paul. Facial expression and emotion. American Psychologist, v. 48, n. 4, p. 384, 1993.

[Essa et al, 1995] ESSA, Irfan Aziz; PENTLAND, Alex P. Facial expression recognition using a dynamic model and motion energy. In: Computer Vision, 1995. Proceedings., Fifth International Conference on. IEEE, 1995. p. 360-367.

[Essa et al, 1997] ESSA, Irfan A.. ; PENTLAND, Alex Paul. Coding, analysis, interpretation, and recognition of facial expressions. Pattern Analysis and Machine Intelligence, IEEE Transactions on, v. 19, n. 7, p. 757-763, 1997.

[Essa et al, 1994] ESSA, Irfan Aziz; PENTLAND, Alexander. A vision system for observing and extracting facial action parameters. In: Computer Vision and Pattern Recognition, 1994. Proceedings CVPR'94., 1994 IEEE Computer Society Conference on. IEEE, 1994. p. 76-83

[Ernst et al, 2009] ERNST, Andreas; RUF, Tobias; KUEBLBECK, Christian. A modular framework to detect and analyze faces for audience measurement systems. In: 2nd Workshop on Pervasive Advertising at Informatik. 2009. p. $75-87$

[Fasel et al, 2000] FASEL, Beat; LUETTIN, Juergen. Recognition of asymmetric facial action unit activities and intensities. In: Pattern Recognition, 2000. Proceedings. 15th International Conference on. IEEE, 2000. p. 11001103. 
[Fasel et al, 2003] FASEL, Beat; LUETTIN, Juergen. Automatic facial expression analysis: a survey. Pattern Recognition, v. 36, n. 1, p. 259-275, 2003.

[Feldman, 1993] FELDMAN, Lisa A. Distinguishing depression and anxiety in self-report: evidence from confirmatory factor analysis on nonclinical and clinical samples. Journal of Consulting and Clinical Psychology, v. 61, n. 4 , p. $631,1993$.

[Frank, 1988] FRANK, Robert H. Passions within reason: The strategic role of the emotions. New York: WW Norton \& Co, 1988.

[Gonçalves et al, 2011A] GONÇALVES, Rafael AM et al. Determinação da Emoção Demonstrada pelo Interlocutor. In: Anais do XXXI CONGRESSO DA SOCIEDADE BRASILEIRA DE COMPUTAÇÃO - Encontro Nacional de Inteligência Artificial. 2011. p. 737-748.

[Gonçalves et al, 2011B] GONÇALVES Rafael A.M., et al. A Dynamic Model for Identification of Emotional Expressions Polibits p. 25-29, 2011.

[Gonçalves et al, 2012]GONÇALVES, Rafael AM et al. A model for inference of emotional state based on facial expressions. Journal of the Brazilian Computer Society, p. 1-11, 2012.

[Griffiths, 1997] GRIFFITHS, P. (1997). What Emotions Really Are: The Problem of Psychological Categories. Chicago: University of Chicago Press.

[Hess et al, 1992] HESS, Ursula et al. The facilitative effect of facial expression on the self-generation of emotion. International Journal of Psychophysiology, v. 12, n. 3, p. 251-265, 1992.

[Hjelmås et al, 2001] HJELMÅS, Erik; LOW, Boon Kee. Face detection: A survey. Computer vision and image understanding, v. 83 , n. 3, p. 236-274, 2001

[lzard, 1971] IZARD, C. E. (1971). The Face of Emotion. New York: AppletonCentury Crofts.

[James, 1884] JAMES, B. W. (1884). What is an Emotion? Perception, p. 114.

[Jones et al, 2003] JONES, Michael; VIOLA, Paul. Fast multi-view face detection. Mitsubishi Electric Research Lab TR-20003-96, v. 3, 2003.

[Kurth et al, 2010] KURTH, Florian et al. A link between the systems: functional differentiation and integration within the human insula revealed by metaanalysis. Brain Structure and Function, v. 214, n. 5, p. 519-534, 2010. 
[Kant et al, 1785] KANT, Immanuel; ELLINGTON, James Wesley. Grounding for the metaphysics of morals; with, On a supposed right to lie because of philanthropic concerns. 1785, Hackett Publishing Company Incorporated, 1993

[Laros et al, 2005] LAROS, Fleur JM; STEENKAMP, Jan-Benedict EM. Emotions in consumer behavior: a hierarchical approach. Journal of business Research, v. 58, n. 10, p. 1437-1445, 2005.

[Lazarus, 2001] LAZARUS, R. S.. Relational meaning and discrete emotions. In K. Scherer, A. Schorr, \& T. Johnstone (Eds.), Appraisal Processes in Emotion - Theory, Methods, Research. Oxford University Press, 2001

[Lien et al, 1998] LIEN, James J. et al. Automated facial expression recognition based on FACS action units. In: Automatic Face and Gesture Recognition, 1998. Proceedings. Third IEEE International Conference on. IEEE, 1998. p. 390-395.

[LiKamWa et al, 2011] LIKAMWA, Robert et al. Can Your Smartphone Infer Your Mood. In:PhoneSense workshop. 2011.

[Martin et al, 2006] MARTIN, Olivier et al. The enterface'05 audio-visual emotion database. In: Data Engineering Workshops, 2006. Proceedings. 22nd International Conference on. IEEE, 2006. p. 8-8.

[MacLean, 1952] MACLEAN, P. Some psychiatric implications of psychological studies on frontotemporal portion of the limbic system (visceral brain). Electroencephalog. Clin. Neuropsysiol., (4), 407-418, 1952.

[Martinez-Miranda et al, 2005] MARTINEZ-MIRANDA, Juan; ALDEA, Arantza. Emotions in human and artificial intelligence. Computers in Human Behavior, v. 21, n. 2, p. 323-341, 2005.

[Matsumoto, 1990] MATSUMOTO, David. Cultural similarities and differences in display rules.Motivation and Emotion, v. 14, n. 3, p. 195-214, 1990.

[Mühlberger et al, 2011] MÜHLBERGER, Andreas et al. Stop looking angry and smile, please: start and stop of the very same facial expression differentially activate threat-and reward-related brain networks. Social cognitive and affective neuroscience, v. 6, n. 3, p. 321-329, 2011.

[Neu, 1977] NEU, Jerome. Emotion, Thought, \& Therapy: A Study of Hume and Spinoza and the Relationship of Philosophical Theories of the Emotions to Psychological Theories of Therapy. University of California Press, 1977.

[Oatley, 1999] OATLEY, K. Emotions. In R. A. Wilson \& F. C. Keil (Eds.), The MIT Encyclopedia of the Cognitive Sciences (1st ed., pp. $273-275$ ). Cambridge: The MIT Press, 1999. 
[Ortony et al, 1990] ORTONY, Andrew; TURNER, Terence J. What's basic about basic emotions?. Psychological review, v. 97, n. 3, p. 315, 1990.

[Pantic et al, 2000A] PANTIC, Maja; ROTHKRANTZ, Leon J.. M.. . Automatic analysis of facial expressions: The state of the art. Pattern Analysis and Machine Intelligence, IEEE Transactions on, v. 22, n. 12, p. 1424-1445, 2000.

[Pantic et al, 2000B] PANTIC, Maja; ROTHKRANTZ, Leon JM. Expert system for automatic analysis of facial expressions. Image and Vision Computing, v. 18, n. 11, p. 881-905, 2000.

[Panksepp, 1998] PANKSEPP, J. (1998). Affective neuroscience: the foundations of human and animal emotions (p. 480). Oxford University Press, 2004.

[Pentland et al, 1994] PENTLAND, Alexander; MOGHADDAM, Baback; STARNER, Thad. View-based and modular eigenspaces for face recognition. In: Computer Vision and Pattern Recognition, 1994. Proceedings CVPR'94., 1994 IEEE Computer Society Conference on. IEEE, 1994. p. 84-91.

[Piccard, 2003] PICARD, Rosalind W. Affective computing: challenges. International Journal of Human-Computer Studies, v. 59, n. 1, p. 5564, 2003.

[Picard, 1995] PICARD, R. W. (1995). Affective Computing. M.I.T Media Laboratory Perceptual Computing Section Technical Report No. $321,1995$.

[Russel, 1994] RUSSELL, James A. Is there universal recognition of emotion from facial expressions? A review of the cross-cultural studies. Psychological bulletin, v. 115, n. 1, p. 102, 1994.

[Sander et al, 2005] SANDER, David; GRANDJEAN, Didier; SCHERER, Klaus R. 2005 Special Issue: A systems approach to appraisal mechanisms in emotion. Neural networks, v. 18, n. 4, p. 317-352, 2005.

[Schachter et al, 1962]SCHACHTER, Stanley; SINGER, Jerome. Cognitive, social, and physiological determinants of emotional state. Psychological Review; Psychological Review, v. 69, n. 5, p. 379, 1962.

[Scherer, 2001] SCHERER, Klaus R. Appraisal considered as a process of multilevel sequential checking. Appraisal processes in emotion: Theory, methods, research, v. 92, p. 120, 2001.

[Sebe, 2007] SEBE, Nicu et al. Authentic facial expression analysis. Image and Vision Computing, v. 25, n. 12, p. 1856-1863, 2007. 
[Simoncelli, 1993] SIMONCELLI, Eero Peter et al. Distributed representation and analysis of visual motion. 1993. Tese de Doutorado. Massachusetts Institute of Technology, Dept. of Electrical Engineering and Computer Science.

[de Sousa, 1990] DE SOUSA, Ronald. The rationality of emotion. Cambridge, MA: MIT Press, 1990.

[de Sousa, 2010] de Sousa, R. (2010). Emotion. The Stanford Encyclopedia of Philosophy. Obtido em

http://plato.stanford.edu/archives/spr2010/entries/emotion/, Último acesso 03/10/2011

[Viola et al, 2004] VIOLA, Paul; JONES, Michael J. Robust real-time face detection.International journal of computer vision, v. 57 , n. 2, p. 137-154, 2004.

[Wollheim, 1999] WOLLHEIM, Richard. On the emotions. Yale University Press, 1999.

[Zeeman, 1976] ZEEMAN, E. Christopher. Catastrophe theory. Scientific American, v. 234, n. 4, p. 65-83, 1976.

[Zhang et al, 2011] ZHANG, Cha; ZHANG, Zhengyou. A survey of recent advances in face detection. Microsoft Research, June, 2010. 